Cochrane Database of Systematic Reviews

\title{
Zinc supplementation for tinnitus (Review)
}

Person OC, Puga MES, da Silva EMK, Torloni MR

Person OC, Puga MES, da Silva EMK, Torloni MR.

Zinc supplementation for tinnitus.

Cochrane Database of Systematic Reviews 2016, Issue 11. Art. No.: CD009832.

DOI: 10.1002/14651858.CD009832.pub2.

www.cochranelibrary.com 
TABLE OF CONTENTS

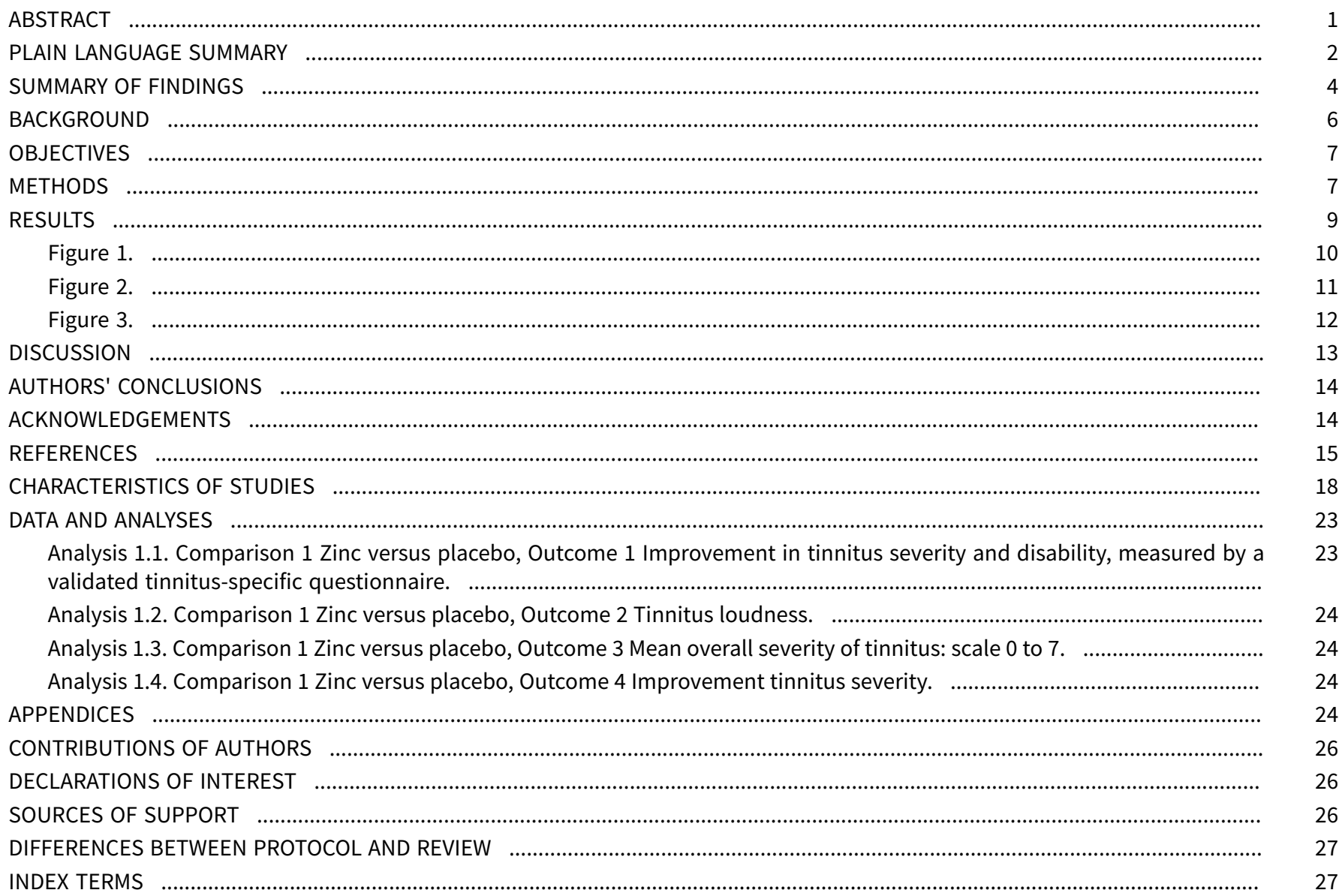


[Intervention Review]

\section{Zinc supplementation for tinnitus}

Osmar C Person ${ }^{1}$, Maria ES Puga², Edina MK da Silva ${ }^{3}$, Maria R Torloni2

1Medicina, Medical School, Universidade Federal de São Paulo, São Paulo, Brazil. 2Brazilian Cochrane Centre, Centro de Estudos de Saúde Baseada em Evidências e Avaliação Tecnológica em Saúde, São Paulo, Brazil. ${ }^{3}$ Emergency Medicine and Evidence Based Medicine, Universidade Federal de São Paulo, São Paulo, Brazil

Contact: Osmar C Person, Medicina, Medical School, Universidade Federal de São Paulo, Rua Pedro de Toledo, 598, São Paulo, São Paulo, 04039-001, Brazil. ocperson@ig.com.br.

Editorial group: Cochrane ENT Group.

Publication status and date: New, published in Issue 11, 2016.

Citation: Person OC, Puga MES, da Silva EMK, Torloni MR. Zinc supplementation for tinnitus. Cochrane Database of Systematic Reviews 2016, Issue 11. Art. No.: CD009832. DOI: 10.1002/14651858.CD009832.pub2.

Copyright @ 2016 The Cochrane Collaboration. Published by John Wiley \& Sons, Ltd.

\section{A B S T R A C T}

\section{Background}

Tinnitus is the perception of sound without external acoustic stimuli. Patients with severe tinnitus may have physical and psychological complaints and their tinnitus can cause deterioration in their quality of life. At present no specific therapy for tinnitus has been found to be satisfactory in all patients. In recent decades, a number of reports have suggested that oral zinc supplementation may be effective in the management of tinnitus. Since zinc has a role in cochlear physiology and in the synapses of the auditory system, there is a plausible mechanism of action for this treatment.

\section{Objectives}

To evaluate the effectiveness and safety of oral zinc supplementation in the management of patients with tinnitus.

\section{Search methods}

The Cochrane ENT Information Specialist searched the ENT Trials Register; Central Register of Controlled Trials (CENTRAL 2016, Issue 6); PubMed; EMBASE; CINAHL; Web of Science; ClinicalTrials.gov; ICTRP and additional sources for published and unpublished trials. The date of the search was 14 July 2016.

\section{Selection criteria}

Randomised controlled trials comparing zinc supplementation versus placebo in adults (18 years and over) with tinnitus.

\section{Data collection and analysis}

We used the standard methodological procedures recommended by Cochrane. Our primary outcome measures were improvement in tinnitus severity and disability, measured by a validated tinnitus-specific questionnaire, and adverse effects. Secondary outcomes were quality of life, change in socioeconomic impact associated with work, change in anxiety and depression disorders, change in psychoacoustic parameters, change in tinnitus loudness, change in overall severity of tinnitus and change in thresholds on pure tone audiometry. We used GRADE to assess the quality of the evidence for each outcome; this is indicated in italics.

\section{Main results}

We included three trials involving a total of 209 participants. The studies were at moderate to high risk of bias. All included studies had differences in participant selection criteria, length of follow-up and outcome measurement, precluding a meta-analysis. The participants were all adults over 18 years with subjective tinnitus, but one study conducted in $2013(n=109)$ included only elderly patients.

Improvement in tinnitus severity and disability 
Only the study in elderly patients used a validated instrument (Tinnitus Handicap Questionnaire) for this primary outcome. The authors of this cross-over study did not report the results of the two phases separately and found no significant differences in the proportion of patients reporting tinnitus improvement at four months of follow-up: $5 \%$ (5/93) versus $2 \%$ (2/94) in the zinc and placebo groups, respectively (risk ratio (RR) $2.53,95 \%$ confidence interval (CI) 0.50 to 12.70 ; very low-quality evidence).

None of the included studies reported any significant adverse effects.

\section{Secondary outcomes}

For the secondary outcome change in tinnitus loudness, one study reported no significant difference between the zinc and placebo groups after eight weeks: mean difference in tinnitus loudness $-9.71 \mathrm{~dB}(95 \% \mathrm{Cl}-25.53$ to 6.11 ; very low-quality evidence). Another study also measured tinnitus loudness but used a 0- to 100-point scale. The authors of this second study reported no significant difference between the zinc and placebo groups after four months: mean difference in tinnitus loudness rating scores $0.50(95 \% \mathrm{Cl}-5.08$ to 6.08 ; very lowquality evidence).

Two studies used unvalidated instruments to assess tinnitus severity. One (with 50 participants) reported the severity of tinnitus using a non-validated scale ( 0 to 7 points) and found no significant difference in subjective tinnitus scores between the zinc and placebo groups at the end of eight weeks of follow-up (mean difference (MD) $-1.41,95 \% \mathrm{Cl}-2.97$ to 0.15 ; very low-quality evidence). A third trial $(n=50)$ also evaluated the improvement of tinnitus using a non-validated instrument (a 0 to 10 scale: $10=$ severe and unbearable tinnitus). In this study, after eight weeks there was no difference in the proportion of patients with improvement in their tinnitus, $8.7 \%(2 / 23)$ treated with zinc versus $8 \%(2 / 25)$ of those who received a placebo (RR $1.09,95 \% \mathrm{Cl} 0.17$ to 7.10 , very low-quality evidence).

None of the included studies reported any of our other secondary outcomes (quality of life, change in socioeconomic impact associated with work, change in anxiety and depression disorders, change in psychoacoustic parameters or change in thresholds on pure tone audiometry).

\section{Authors' conclusions}

We found no evidence that the use of oral zinc supplementation improves symptoms in adults with tinnitus.

\section{PLAIN LANGUAGE SUMMARY}

\section{Zinc supplements for tinnitus}

\section{Background}

Tinnitus is the perceived sensation of sound in the ear or head. Severe tinnitus affects $1 \%$ to $2 \%$ of the population. People with severe tinnitus frequently have psychological changes and a decrease in their quality of life. Tinnitus is difficult to control and many doctors are testing new treatments to improve the quality of life of people who suffer from this problem. This review looked for high-quality studies in the literature that involved zinc supplements as a possible treatment for tinnitus in adults. The aim was to evaluate whether oral zinc is effective in the treatment of tinnitus.

\section{Study characteristics}

We included a total of three trials involving 209 participants who were treated with oral zinc pills or placebo. All patients were adults over 18 years who had subjective tinnitus. All three studies investigated improvement in tinnitus as their primary outcome. One study assessed adverse effects and our secondary outcome 'change in overall severity of tinnitus'. Two studies assessed tinnitus loudness. Only one study, which enrolled only elderly patients, used a validated instrument (the Tinnitus Handicap Questionnaire (THQ)) to measure the primary outcome. The other two studies measured tinnitus using scales (from 0 to 7 and from 0 to 10), but these scales were not validated instruments for studying tinnitus.

\section{Key results}

All three included studies had differences in their participant selection, length of follow-up and outcome measurement, which prevented a meta-analysis (combining of results).

Only one trial (conducted in 2013) used a validated instrument (the THQ) to measure improvement in tinnitus, our primary outcome. The authors reported no significant difference between the groups. Another study (2003) reported the severity of tinnitus using a non-validated scale ( 0 to 7 ) and found a significant difference in the subjective tinnitus scores, which favoured the zinc group. However, this result may be biased because the losses were unbalanced and higher in the placebo group. A third study (1991) also evaluated improvement of tinnitus using a non-validated instrument (a scale of 0 to 10) and found no significant difference between groups.

There were no severe adverse effects associated with zinc. Three cases of mild adverse effects were reported in different participants (e.g. mild gastric symptoms). 
Two studies (2003 and 2013) assessed change in tinnitus loudness (one of our secondary outcomes), but did not find a difference between patients treated with zinc compared to those who took a placebo.

Two studies assessed change in the overall severity of tinnitus. One study, published in 1991, did not find any difference for this outcome between the groups. The second study, published in 2003, reported a significant reduction in subjective tinnitus score in the zinc group and no difference in the placebo group. However, both studies used a non-validated scale.

\section{Quality of the evidence}

The quality of the evidence is very low. We found no evidence that the use of oral zinc supplementation improves symptoms in adults with tinnitus. This evidence is up to date to 14 July 2016. 


\section{SUMMARY OF FINDINGS}

\section{Summary of findings for the main comparison.}

Zinc supplementation compared with placebo for tinnitus

Patient or population: adults over 18 years with tinnitus

Settings: outpatient clinics in universities

Intervention: zinc supplementation

Comparison: placebo

\begin{tabular}{|c|c|c|c|c|c|c|}
\hline \multirow[t]{3}{*}{ Outcomes } & \multicolumn{2}{|c|}{$\begin{array}{l}\text { Illustrative comparative risks* }(95 \% \\
\mathrm{CI})\end{array}$} & \multirow[t]{3}{*}{$\begin{array}{l}\text { Relative effect } \\
(95 \% \mathrm{CI})\end{array}$} & \multirow{3}{*}{$\begin{array}{l}\text { No of partici- } \\
\text { pants } \\
\text { (studies) }\end{array}$} & \multirow{3}{*}{$\begin{array}{l}\text { Quality of the } \\
\text { evidence } \\
\text { (GRADE) }\end{array}$} & \multirow[t]{3}{*}{ Comments } \\
\hline & Assumed risk & $\begin{array}{l}\text { Corresponding } \\
\text { risk }\end{array}$ & & & & \\
\hline & Placebo & Zinc & & & & \\
\hline \multirow{2}{*}{$\begin{array}{l}\text { Improvement in tinnitus severity and disabil- } \\
\text { ity, measured by a validated tinnitus-specific } \\
\text { questionnaire (THQ) }\end{array}$} & \multicolumn{2}{|c|}{ Medium risk population } & \multirow[t]{3}{*}{$2.53(0.50$ to 12.70$)$} & \multirow{3}{*}{$\begin{array}{l}187 \text { participants } \\
\text { ( } 1 \text { study) }\end{array}$} & \multirow{3}{*}{$\begin{array}{l}\oplus \ominus \ominus \ominus \\
\text { very low } \mathbf{1 , 2 , 3}\end{array}$} & \multirow[t]{3}{*}{-} \\
\hline & 21 per 1000 & $\begin{array}{l}53 \text { per } 1000 \\
\text { (10 to } 267)\end{array}$ & & & & \\
\hline $\begin{array}{l}\text { Proportion of patients improved } \\
4 \text { months }\end{array}$ & & & & & & \\
\hline Adverse effects of treatment & Not reported & Not reported & Not reported & Not reported & - & - \\
\hline Quality of life & Not reported & Not reported & Not reported & Not reported & - & - \\
\hline Anxiety and depression disorders & Not reported & Not reported & Not reported & Not reported & - & - \\
\hline Psychoacoustic parameters & Not reported & Not reported & Not reported & Not reported & - & - \\
\hline Tinnitus loudness (dB) & - & - & MD -9.71 & 41 & $\oplus \ominus \ominus \ominus$ & - \\
\hline 8 weeks & & & $(-25.53$ to 6.11$)$ & (1) & very low $1,2,3$ & \\
\hline 0 to 100 scale & & & MD 0.50 & 116 & & \\
\hline
\end{tabular}


*The basis for the assumed risk (e.g. the median control group risk across studies) is provided in footnotes. The corresponding risk (and its $95 \%$ confidence interval) is based on the assumed risk in the comparison group and the relative effect of the intervention (and its $95 \% \mathrm{Cl}$ ).

Cl: confidence interval; RR: risk ratio; THQ: Tinnitus Handicap Questionnaire

GRADE Working Group grades of evidence

High quality: Further research is very unlikely to change our confidence in the estimate of effect.

Moderate quality: Further research is likely to have an important impact on our confidence in the estimate of effect and may change the estimate.

Low quality: Further research is very likely to have an important impact on our confidence in the estimate of effect and is likely to change the estimate.

Very low quality: We are very uncertain about the estimate.

1Downgraded one level due to publication bias because few studies were identified.

2Downgraded one level due to risk of selection bias (unclear randomisation method).

${ }^{3}$ Downgraded one level due to imprecision because the sample size was small. 


\section{B A C K G R O U N D}

The following paragraphs and Description of the condition are based on the Cochrane Review 'Amplification with hearing aids for patients with tinnitus and co-existing hearing loss' and reproduced with permission (Hoare 2014).

Tinnitus is defined as the perception of sound in the absence of an external source (Jastreboff 2004). It is typically described by those who experience it as a ringing, hissing, buzzing or whooshing sound and is thought to result from abnormal neural activity at some point or points in the auditory pathway, which is erroneously interpreted by the brain as sound. Tinnitus can be either objective or subjective. Objective tinnitus refers to the perception of sound that can also be heard by the examiner and is usually due to blood flow or muscle movement (Eggermont 2010). Most commonly, however, tinnitus is subjective; the sound is only heard by the person experiencing it and no source of the sound is identified (Jastreboff 1988).

Subjective tinnitus affects $10 \%$ of the general population, increasing to as many as $30 \%$ of adults over the age of 50 years (Davis 2000; Møller 2000). It can be experienced acutely, recovering spontaneously within minutes to weeks, but is considered chronic and unlikely to resolve spontaneously when experienced for three months or more (Hahn 2008; Hall 2011; Rief 2005).

In England alone there are an estimated $3 / 4$ million general practitioner (GP) consultations every year where the primary complaint is tinnitus (El-Shunnar 2011), equating to a major burden on healthcare services. For many people tinnitus is persistent and troublesome, and has disabling effects such as insomnia, difficulty concentrating, difficulties in communication and social interaction, and negative emotional responses such as anxiety and depression (Andersson 2009; Crönlein 2007; Marciano 2003). In approximately $90 \%$ of cases, chronic tinnitus is co-morbid with some degree of hearing loss, which may confound these disabling effects (Fowler 1944; Sanchez 2002). An important implication of this in clinical research, therefore, is that outcome measures need to distinguish benefits specific to improved hearing from those specific to tinnitus.

\section{Description of the condition}

\section{Diagnosis and clinical management of tinnitus}

There is no standard procedure for the diagnosis or management of tinnitus. Practice guidelines and the approaches described in studies of usual clinical practice typically reflect differences between the clinical specialisms of the authors or differences in the clinical specialisms charged with meeting tinnitus patients' needs (medical, audiology/hearing therapy, clinical psychology, psychiatry), or the available resources of a particular country or region (access to clinicians or devices, for example) (Biesinger 2011; Cima 2012; Department of Health 2009; Hall 2011; Henry 2008; Hoare 2011a). Common across all these documents, however, is the use or recommendation of written questionnaires to assess tinnitus and its impact on patients by measuring severity, quality of life, depression or anxiety. Psychoacoustic measures of tinnitus (pitch, loudness, minimum masking level) are also recommended. Although these measures do not correlate well with tinnitus severity (Hiller 2006), they can prove useful in patient counselling (Henry 2004), or by demonstrating stability of the tinnitus percept over time (Department of Health 2009).
Clinical management strategies include education and advice, relaxation therapy, tinnitus retraining therapy (TRT), cognitive behavioural therapy (CBT), sound enrichment using ear-level sound generators or hearing aids, and drug therapies to manage co-morbid symptoms such as insomnia, anxiety or depression. The effects of these management options are variable and they have few known risks or adverse effects (Dobie 1999; Hoare 2011; Hobson 2012; Martinez-Devesa 2010; Phillips 2010).

\section{Pathophysiology}

Most people with chronic tinnitus have some degree of hearing loss (Ratnayake 2009), and the prevalence of tinnitus increases with greater hearing loss (Han 2009; Martines 2010). The varying theories of tinnitus generation involve changes in either function or activity of the peripheral (cochlea and auditory nerve) or central auditory nervous systems (Henry 2005). Theories involving the peripheral systems include the discordant damage theory, which predicts that the loss of outer hair cell function, where inner hair cell function is left intact, leads to a release from inhibition of inner hair cells and aberrant activity (typically hyperactivity) in the auditory nerve (Jastreboff 1990). Such aberrant auditory nerve activity can also have a biochemical basis, resulting from excitotoxicity or stressinduced enhancement of inner hair cell glutamate release with up-regulation of N-methyl-D-aspartate (NMDA) receptors (Guitton 2003; Sahley 2001).

In the central auditory system, structures implicated as possible sites of tinnitus generation include the dorsal cochlear nucleus (Middleton 2011; Pilati 2012), the inferior colliculus (Dong 2010; Mulders 2010), and the auditory and non-auditory cortex (discussed further below). There is a strong rationale that tinnitus is a direct consequence of maladaptive neuroplastic responses to hearing loss (Møller 2000; Mühlnickel 1998). This process is triggered by sensory deafferentation and a release from lateral inhibition in the central auditory system allowing irregular spontaneous hyperactivity within the central neuronal networks involved in sound processing (Eggermont 2004; Rauschecker 1999; Seki 2003). As a consequence of this hyperactivity, a further physiological change noted in tinnitus patients is increased spontaneous synchronous activity occurring at the cortical level, measurable using electroencephalography (EEG) or magnetoencephalography (MEG) (Dietrich 2001; Tass 2012; Weisz 2005). Another physiological change thought to be involved in tinnitus generation is a process of functional reorganisation, which amounts to a change in the response properties of neurons within the primary auditory cortex to external sounds. This effect is well demonstrated physiologically in animal models of hearing loss (Engineer 2011; Noreña 2005). Evidence in humans, however, is limited to behavioural evidence of cortical reorganisation after hearing loss, demonstrating improved frequency discrimination ability at the audiometric edge (Kluk 2006; McDermott 1998; Moore 2009; Thai-Van 2002; Thai-Van 2003), although Buss 1998 did not find this effect. For comprehensive reviews of these physiological models, see Adjamian 2009 and Noreña 2005.

It is also proposed that spontaneous hyperactivity could cause an increase in sensitivity or 'gain' at the level of the cortex, whereby neural sensitivity adapts to the reduced sensory inputs, in effect stabilising mean firing and neural coding efficiency (Noreña 2011; Schaette 2006; Schaette 2011). Such adaptive changes would be achieved at the cost of amplifying 'neural noise' due to the overall 
increase in sensitivity, ultimately resulting in the generation of tinnitus.

Increasingly, non-auditory areas of the brain, particularly areas associated with emotional processing, are also implicated in bothersome tinnitus (Rauschecker 2010; Vanneste 2012). Vanneste 2012 describes tinnitus as "an emergent property of multiple parallel dynamically changing and partially overlapping subnetworks", implicating the involvement of many structures of the brain more associated with memory and emotional processing in tinnitus generation. However, identification of the structural components of individual neural networks responsible for either tinnitus generation or tinnitus intrusiveness, which are independent of those for hearing loss, remains open to future research (Melcher 2013).

One further complication in understanding the pathophysiology of tinnitus is that not all people with hearing loss have tinnitus and not all people with tinnitus have a clinically significant hearing loss. Other variables, such as the profile of a person's hearing loss, may account for differences in their tinnitus report. For example, König 2006 found that the maximum slope within audiograms was higher in people with tinnitus than in people with hearing loss who do not have tinnitus, despite the 'non-tinnitus' group having the greater mean hearing loss. This suggests that a contrast in sensory inputs between regions of normal and elevated threshold may be more likely to result in tinnitus.

The intensity and consequences of tinnitus may be measured in different ways (see Appendix 1; 'Tinnitus measurement tools').

\section{Description of the intervention}

Zinc is an important oligoelement involved in several physiological functions including central neurotransmission (Gersdorff 1987). Copper/zinc superoxide dismutase ( $\mathrm{Cu} / \mathrm{Zn}$ SOD) is a first-line defence against free radical damage in the cochlea (MacFadden 1999). Zinc is involved in several other important physiological systems, such as the Na-K-ATPase pump. Deficiency of this trace element can modify endocochlear potentials, affect cochlear electrophysiology and generate tinnitus. In 1987, Gersdorf hypothesised that altered zinc physiology could be related to tinnitus generation (Gersdorff 1987), and in 1991 the systemic administration of zinc was tested as an alternative treatment for this condition (Paaske 1991). The existence of a correlation between progressive sensorineural hearing loss, similar to presbyacusis, tinnitus and serum hypozincaemia has been suggested (Shambaugh 1985).

Zinc is absorbed in the small intestine, especially in the jejunum and ileum, but it is still unclear how it enters into cochlear cells. Some authors have suggested, based on their clinical practice, that some patients have improvement of their tinnitus with oral administration of zinc compounds, especially elderly people (Person 2004; Shambaugh 1986). The assessment of serological zinc levels before metal replacement therapy is not recommended because clinical improvement of tinnitus has been observed in patients with low, normal or elevated zinc levels (Person 2004).

\section{How the intervention might work}

Glutamate is the presumed neurotransmitter in inner hair cells (Drescher 1992) and central auditory pathways (Person 2004). Abnormalities in synaptic transmission between these cells and the cochlear nerve could increase the spontaneous activity of neural fibres, generating tinnitus (Jastreboff 1990). Zinc, an oligoelement present in the auditory system, is involved in glutamatergic excitation of synaptic networks. This metal seems to act on the post-synaptic receptors of some glutamatergic synapses (Frederickson 2000). Thus, by modulating glutamatergic action in the central auditory pathways, zinc could modify tinnitus and reduce the perception of this symptom in some patients. Additionally, the cochlear antioxidant effects of zinc could also be related to the improvement of tinnitus in some patients (Person 2010).

\section{Why it is important to do this review}

Zinc deficiency increases with advancing age, especially after the age of 60 , and this could be a factor that predisposes to tinnitus (Shambaugh 1986). Abnormal zinc physiology has been associated with the onset of tinnitus. Systematic administration of zinc has therefore been tested as an alternative treatment for this disorder by several investigators over recent decades (Gersdorff 1987; Person 2004). However, to date there has been no systematic assessment of these studies. This review is important because it critically appraises and synthesises the best available evidence on the efficacy of zinc supplementation in the treatment of tinnitus in adults. This information could be useful for optimising the treatment of these patients and potentially reducing costs.

\section{O B JECTIVES}

To evaluate the effectiveness and safety of oral zinc supplementation in the management of patients with tinnitus.

\section{METHODS}

\section{Criteria for considering studies for this review \\ Types of studies}

Randomised controlled trials (including those with a cross-over design).

\section{Types of participants}

Adults over 18 years.

\section{Types of interventions}

Oral zinc supplementation alone, in any dose or frequency, versus placebo, for the treatment of tinnitus.

\section{Types of outcome measures}

We analysed the following outcomes in the review, but we did not use them as a basis for including or excluding studies.

\section{Primary outcomes}

- Improvement in tinnitus severity and disability, measured by a validated tinnitus-specific questionnaire (Appendix 1).

- Adverse effects of treatment with oral zinc supplementation.

\section{Secondary outcomes}

- Quality of life.

- Change in socioeconomic impact associated with work.

- Change in anxiety and depression disorders. 
- Change in psychoacoustic parameters.

- Change in tinnitus loudness.

- Change in overall severity of tinnitus.

- Change in thresholds on pure tone audiometry.

\section{Search methods for identification of studies}

The Cochrane ENT Information Specialist conducted systematic searches for randomised controlled trials and controlled clinical trials. There were no language, publication year or publication status restrictions. The date of the search was 14 July 2016.

\section{Electronic searches}

The Information Specialist searched:

- the Cochrane ENT Trials Register (searched 14 July 2016);

- the Cochrane Central Register of Controlled Trials (CENTRAL 2016, Issue 6);

- PubMed (1946 to 14 July 2016);

- Ovid EMBASE (1974 to 14 July 2016);

- Ovid CAB Abstracts (1910 to 14 July 2016);

- EBSCO CINAHL (1982 to 14 July 2016);

- Ovid AMED (1985 to 14 July 2016);

- LILACS, lilacs.bvsalud.org (searched 14 July 2016);

- KoreaMed (searched via Google Scholar 14 July 2016);

- IndMed, www.indmed.nic.in (searched 14 July 2016);

- PakMediNet, www.pakmedinet.com (searched 14 July 2016);

- Web of Knowledge, Web of Science (1945 to 14 July 2016);

- CNKI, www.cnki.com.cn (searched via Google Scholar 14 July 2016);

- ClinicalTrials.gov (searched via the Cochrane Register of Studies 14 July 2016);

- World Health Organization (WHO) International Clinical Trials Registry Platform (ICTRP), www.who.int/ictrp (searched 14 July 2016);

- ISRCTN, www.isrctn.com (searched 14 July 2016);

- Google Scholar, scholar.google.co.uk (searched 14 July 2016);

- Google, www.google.com (searched 14 July 2016).

In searches prior to 2013, we also searched BIOSIS Previews 1926 to May 2012.

The Information Specialist modelled subject strategies for databases on the search strategy designed for CENTRAL. Where appropriate, they were combined with subject strategy adaptations of the highly sensitive search strategy designed by Cochrane for identifying randomised controlled trials and controlled clinical trials (as described in the Cochrane Handbook for Systematic Reviews of Interventions Version 5.1.0, Box 6.4.b. (Handbook 2011). Search strategies for major databases including CENTRAL are provided in Appendix 2.

\section{Searching other resources}

We scanned the reference lists of identified publications for additional trials and contacted trial authors where necessary. In addition, the Information Specialist searched PubMed, TRIPdatabase, The Cochrane Library and Google to retrieve existing systematic reviews relevant to this systematic review, so that we could scan their reference lists for additional trials.

\section{Data collection and analysis}

\section{Selection of studies}

Two authors (OCP and MRT) independently screened the citations identified and selected those judged possibly relevant by both for full-text reading. In case of disagreement or uncertainty of study relevance based on title and abstract screening, we also retrieved the full-text article. The two independent review authors read each full paper and assessed each for possible inclusion according to the selection criteria. In case of disagreement, we consulted a third senior review author (EMKS). We listed the reasons for exclusion of all publications selected for full-text reading.

\section{Data extraction and management}

Two independent authors (OCP and MRT) extracted the data. We discussed discrepancies until consensus was reached or with the help of a third author (EMKS). We used a standard form created for this review to extract the following information from each included study:

- characteristics of the study (design, methods of randomisation and information for 'Risk of bias' assessment);

- characteristics of participants (including age, gender, eligibility and exclusion criteria, and baseline characteristics);

- details intervention and comparator;

- outcomes (types of outcome measures, timing of outcome measurement, adverse events);

- funding sources;

- declarations of interest.

If needed, we contacted the authors to obtain further details.

\section{Assessment of risk of bias in included studies}

Two authors (OCP and MRT) independently assessed the included studies for risk of bias. We resolved any disagreement through discussion. As recommended by the Cochrane Handbook for Systematic Reviews of Interventions, we evaluated the following items (Handbook 2011):

- sequence generation;

- allocation concealment;

- blinding;

- incomplete outcome data;

- selective outcome reporting;

- other sources of bias.

We used the Cochrane 'Risk of bias' tool in RevMan 5.3 (RevMan 2014), which involves describing each of these domains as reported in the trial and then assigning a judgment about the adequacy of each entry (low, high or unclear risk of bias).

\section{Measures of treatment effect}

For dichotomous variables, we calculated the risk ratio (RR) and $95 \%$ confidence interval $(\mathrm{Cl})$. For continuous outcomes, we calculated the mean difference (MD) and $95 \% \mathrm{Cl}$. In the event that authors did not make available the necessary information, we intended to insert any data from primary studies that were not parametric (e.g. effects reported as medians, quartiles, etc.) or without sufficient statistical information (e.g. standard deviations, number of patients, etc.) into an additional table. 


\section{Unit of analysis issues}

The unit of analysis was the individual participant (the unit randomised for interventions to be compared), i.e. the number of observations in the analysis matched the number of individuals randomised. For trials with a cross-over design, we would have included the data using the results of paired analyses (Elbourne 2002).

\section{Dealing with missing data}

Irrespective of the type of data, we reported dropout rates in the Characteristics of included studies table and performed intentionto-treat analyses.

\section{Assessment of heterogeneity}

We quantified inconsistency among the pooled estimates using the $1^{2}$ statistic. This illustrates the percentage of the variability in effect estimates resulting from heterogeneity rather than sampling error (Deeks 2011; Higgins 2003). The thresholds for the interpretation of $\mathrm{I}^{2}$ were: $0 \%$ to $25 \%$ low heterogeneity, $25 \%$ to $75 \%$ moderate heterogeneity and more than $75 \%$ significant heterogeneity (Higgins 2003).

\section{Assessment of reporting biases}

We intended to assess publication bias by drawing a funnel plot (trial effect versus trial size), if a sufficient number of studies had been included in the review.

\section{Data synthesis}

For dichotomous variables, we intended to calculate the risk ratio (also known as the relative risk (RR)). For continuous variables, we intended to calculate the mean difference (MD) when studies reported their results using the same variables measured with the same units of measure. If continuous data were relative to the same aspect, but were measured with different instruments (different and not interchangeable units of measure), we would have pooled these data using the standardised mean difference (SMD). For all statistical methods, when pooling data we would have reported the $95 \%$ confidence interval $(95 \% \mathrm{Cl})$.

If no significant heterogeneity had been identified, we would have computed pooled estimates of the treatment effect for each outcome using a fixed-effect model. If significant heterogeneity had been identified, we would have performed a random-effects analysis.

\section{Subgroup analysis and investigation of heterogeneity}

In case of significant heterogeneity, we intended to investigate the possible causes by exploring the impact of study risk of bias and the condition of the individuals. If we had identified the sources of heterogeneity, and if there were sufficient data, we intended to conduct meta-analyses by subgroups (e.g. by different dosage and age of participants).

\section{Sensitivity analysis}

If the number of studies had been sufficient, we intended to perform sensitivity analyses to explore the causes of heterogeneity and the robustness of the results. We would have included the following factors in the sensitivity analyses, grouping studies according to:

- quality of allocation concealment (adequate or unclear or inadequate);

- blinding of participants, caregiver and outcome assessment (adequate or unclear or inadequate or not performed);

- rates of withdrawals for each outcome;

- length of follow-up;

- age of participants.

\section{GRADE and 'Summary of findings' table}

We used the GRADE approach to rate the overall quality of evidence. The quality of evidence reflects the extent to which we are confident that an estimate of effect is correct and we applied this in the interpretation of results. There are four possible ratings: high, moderate, low and very low. A rating of high quality of evidence implies that we are confident in our estimate of effect and that further research is very unlikely to change our confidence in the estimate of effect. A rating of very low quality implies that any estimate of effect obtained is very uncertain.

The GRADE approach rates evidence from RCTs that do not have serious limitations as high quality. However, several factors can lead to the downgrading of the evidence to moderate, low or very low. The degree of downgrading is determined by the seriousness of these factors:

- study limitations (risk of bias);

- inconsistency;

- indirectness of evidence;

- imprecision; and

- publication bias.

We included a 'Summary of findings' table (Summary of findings for the main comparison), constructed according to the recommendations described in Chapter 10 of the Cochrane Handbook for Systematic Reviews of Interventions (Handbook 2011). We included the following outcomes in the 'Summary of findings' table: improvement in tinnitus severity and disability (measured by validated scale), change in tinnitus loudness and change in tinnitus severity (measured by non-validated scale).

\section{RE S U L T S}

\section{Description of studies}

\section{Results of the search}

We ran the searches using the methods set out in the protocol. We identified 87 records from the searches, but this number dropped to 56 once duplicates were removed. After closer examination of the titles and abstracts of these references, we obtained full paper copies for eight citations that were potentially eligible for inclusion in the review. Of these eight citations, three studies fulfilled our inclusion criteria (Arda 2003; Coelho 2013; Paaske 1991). We excluded five studies (see Characteristics of excluded studies). We found no ongoing studies and no studies are awaiting assessment.

Figure 1 depicts the search history. 
Figure 1. Process of study identification and selection.

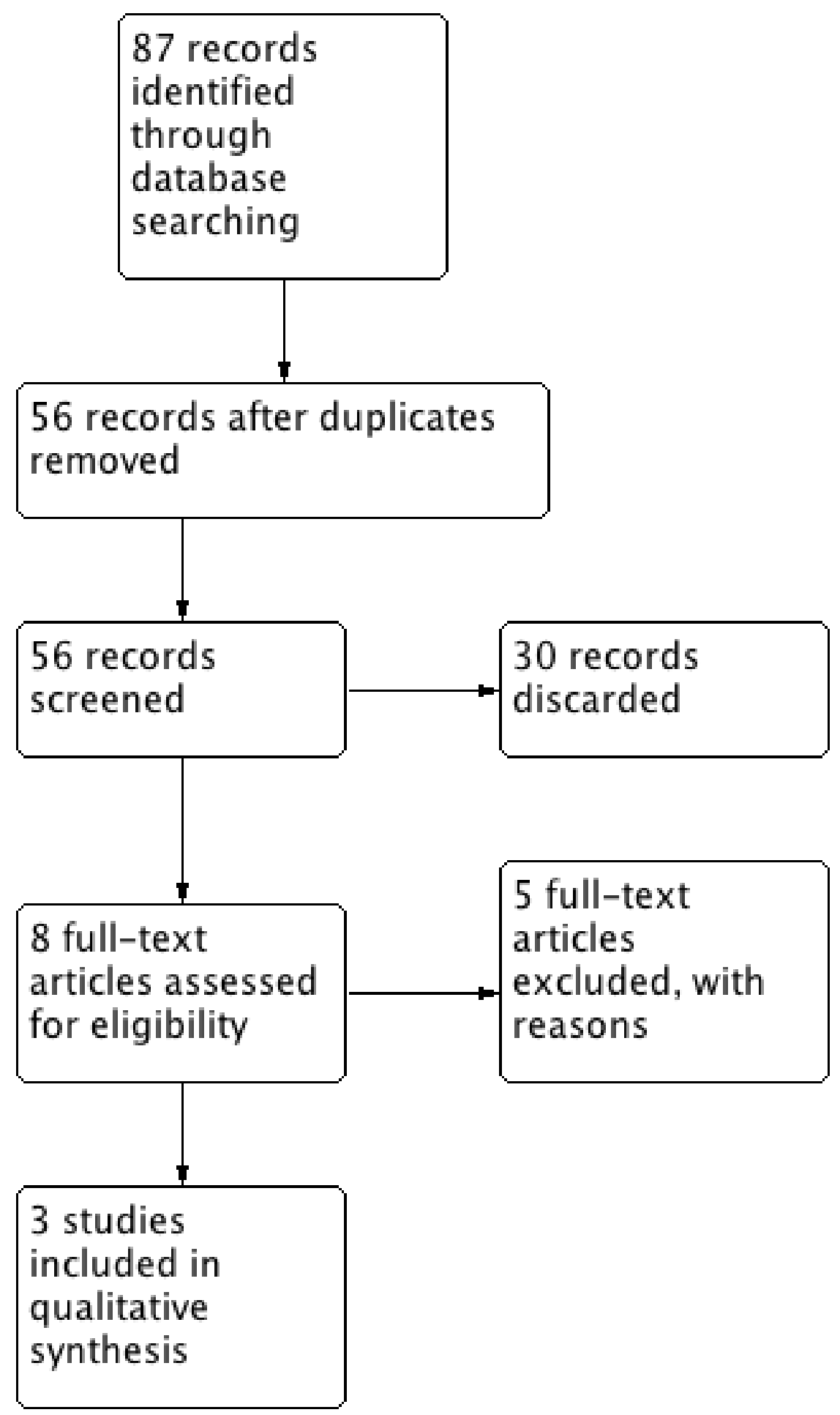

\section{Included studies}

See Characteristics of included studies.

We included three studies (Arda 2003; Coelho 2013; Paaske 1991).
Design

All studies were reported to be placebo-controlled and randomised, but two were unclear in their description of the method of allocation or sequence generation (Arda 2003; Paaske 1991). One was described as being a cross-over, double-blind, clinical trial (Coelho 2013). See Risk of bias in included studies. 


\section{Sample sizes}

A total of 209 participants were included in the three studies, ranging from 50 to 109 individuals per study, with a mean sample size of 69. Sample size calculations were rarely reported and this omission (with probable poor statistical power) was a frequent methodological flaw.

\section{Setting}

All three included studies were conducted in single centres by otolaryngologists in outpatient clinics in universities.

\section{Participants}

All participants were adults over 18 years with subjective tinnitus and living in the community under normal circumstances who were recruited in outpatient clinics. Coelho 2013 included 109 participants with a mean age of 67.5 in the zinc group and 67.7 in the placebo group; $66 \%$ were male. Arda 2003 included 50 patients with an age range of 21 to 74 years. The mean age was $55 \pm 14.3$ in the zinc group and $51.2 \pm 12.8$ in the placebo group. The zinc group included 16 women (57.1\%) and 12 men (42.9\%) and the placebo group included nine women (69.2\%) and four men (30.8\%). Paaske 1991 included 50 patients between 29 to 77 years of age; the median age in the zinc and placebo groups was 60 and 48 years, respectively. Thirty-one patients (65\%) were men.

\section{Interventions}

Each trial included two groups of participants: one was treated with zinc and the other (control group) was given placebo. Coelho 2013 included 109 participants with subjective tinnitus: 54 were treated with elemental zinc ( $50 \mathrm{mg}$ for 16 weeks) and 55 received placebo pills for the same period. After four weeks of washout, 45 patients were treated with zinc and 46 with placebo for 16 weeks. Arda 2003

Figure 2. 'Risk of bias' graph: review authors' judgements about each risk of bias item presented as percentages

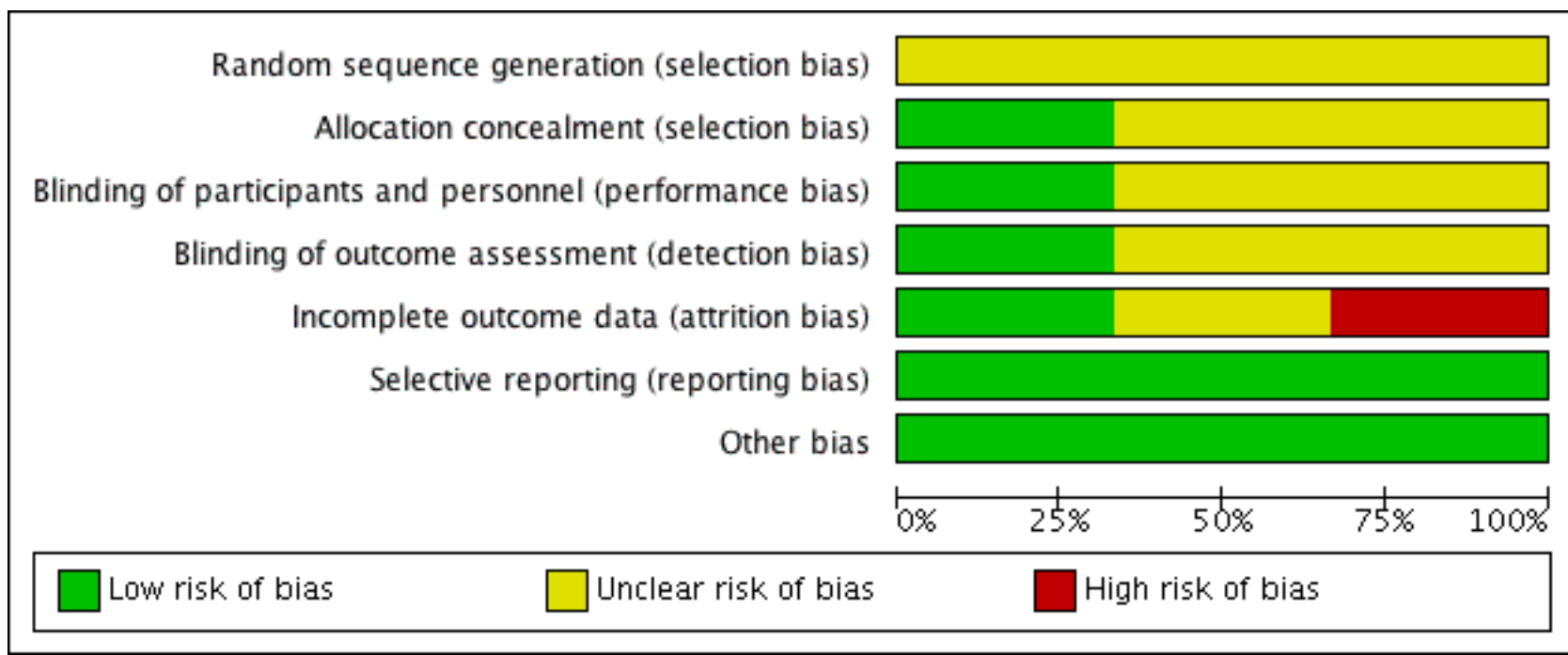

compared two groups of participants (total 50 patients): 30 were treated with zinc (50 mg daily for eight weeks) and 20 were given placebo pills for the same period. Paaske 1991 involved a total of 50 patients. Twenty-five received $66 \mathrm{mg}$ of elemental zinc daily for eight weeks while 25 received a placebo.

\section{Outcomes}

The primary outcome measure was the same in all included studies and involved evaluating the improvement in tinnitus in patients treated with zinc, but there was considerable variation in the specific measures used. Coelho 2013 used a validated instrument (Tinnitus Handicap Questionnaire (THQ)), which measured changes in the score of 20 points or greater to evaluate tinnitus. The other two included studies did not use a validated instrument. To evaluate improvement of tinnitus Arda 2003 used a scale where a decrease in tinnitus loudness by at least $10 \mathrm{~dB}$ was accepted as clinically favourable progress. A decrease of more than one point on a subjective non-validated scale (0 to 7) for tinnitus was accepted as valid. Paaske 1991 used a scale that evaluated the severity of tinnitus measured on a scale of 0 to 10 .

The secondary outcomes measured were the change in tinnitus loudness (Arda 2003; Coelho 2013), and adverse effects of oral zinc treatment (Arda 2003; Coelho 2013). Paaske 1991 did not evaluate any secondary outcomes.

\section{Excluded studies}

We excluded five studies because they were not randomised controlled trials (Gersdorff 1987; Ochi 1997; Ochi 2003; Person 2004; Person 2010). See Characteristics of excluded studies.

\section{Risk of bias in included studies}

See the 'Risk of bias' graph (Figure 2) and 'Risk of bias' summary (Figure 3).

\section{across all included studies.}


Figure 3. 'Risk of bias' summary: review authors' judgements about each risk of bias item for each included study.

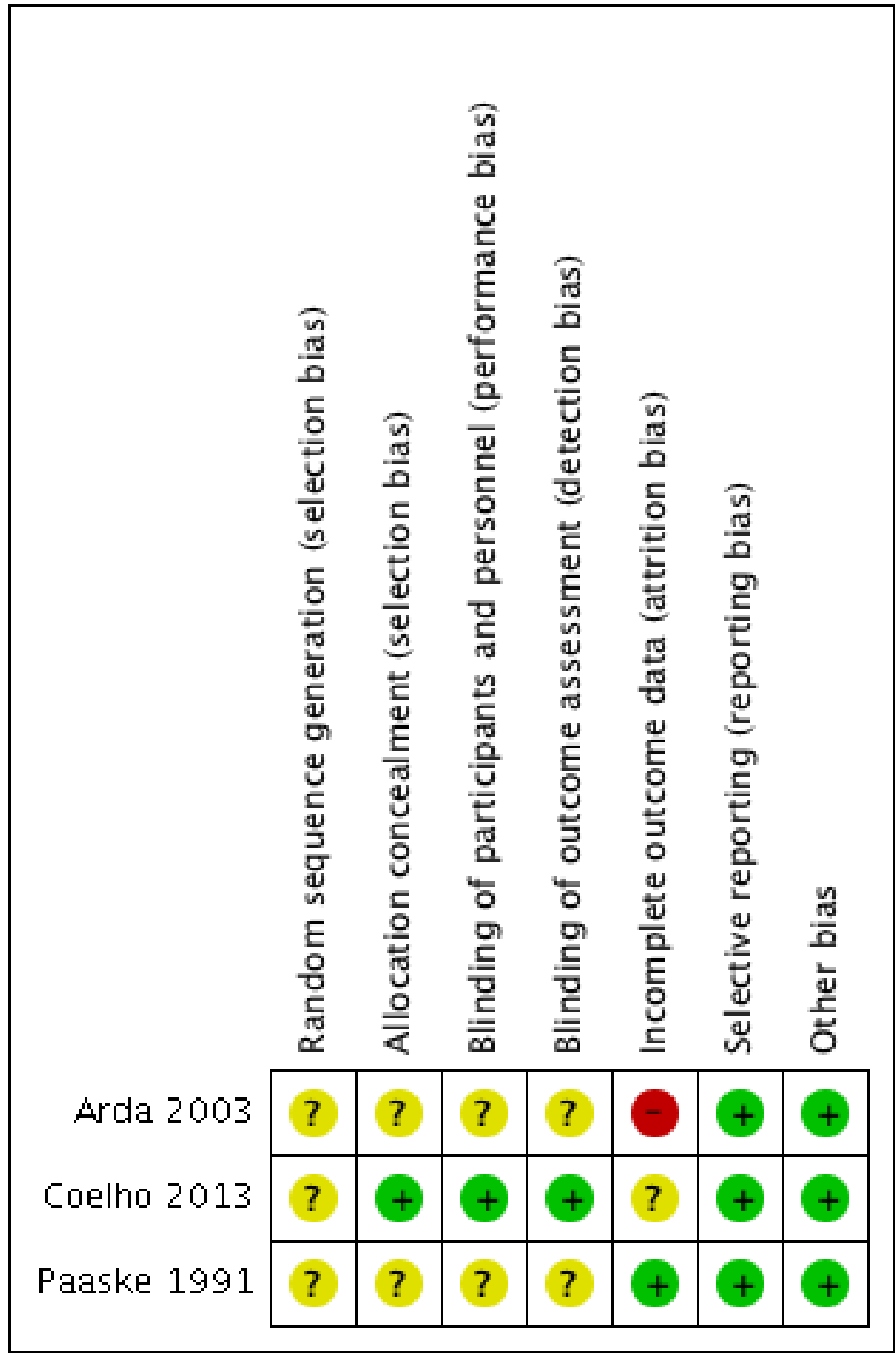

\section{Allocation}

\section{Sequence generation}

None of the included studies described their method of random sequence generation, therefore we judged all of them to have an unclear risk of bias for this domain.

\section{Allocation concealment}

One study described how the patients were allocated to each group by an external department (pharmacy department) and we categorised it as having a low risk of bias for this domain (Coelho 2013). We judged the other two studies to have an unclear risk of bias because allocation concealment was not described (Arda 2003; Paaske 1991).

\section{Blinding}

The blinding of participants and personnel was described in Coelho 2013 (low risk of bias). The other two studies did not describe blinding methods and we therefore judged them to have an unclear risk of bias for this domain (Arda 2003; Paaske 1991).

\section{Incomplete outcome data}

All studies reported withdrawals and dropouts adequately. The dropout rates for intervention and control groups were low in the Paaske 1991 study (4\%) and moderate in Arda 2003 (18\%) and Coelho 2013 (18\%). In Paaske 1991, two participants were excluded because they did not complete the treatment. In Arda 2003, nine participants (two in the zinc group and seven in the control group) were non-compliant in taking their pills. In Coelho 2013, 20 patients 
were excluded because they did not complete the treatment. The risk of bias was low in the Paaske 1991 and Coelho 2013 studies and high in the Arda 2003 study.

\section{Selective reporting}

We classified all studies as low risk of bias. There was no evidence of selective reporting in the included studies based on the comparison of the 'Methods' with the 'Results' section in each study, and all included studies used the primary outcome measure of this review, improvement of the severity of tinnitus; however, only one study used a validated instrument. We identified a registration protocol for only one study (Coelho 2013).

\section{Other potential sources of bias}

We identified no other potential sources of bias.

\section{Effects of interventions}

See: Summary of findings for the main comparison

The three included studies, Arda 2003, Coelho 2013 and Paaske 1991, differed in their participant selection, length of follow-up and outcome measurement, precluding meta-analysis. The results are therefore presented narratively.

See Summary of findings for the main comparison.

\section{Zinc versus placebo}

\section{Primary outcomes}

Improvement in tinnitus severity and disability, measured by a validated tinnitus-specific questionnaire

Only the trial conducted by Coelho 2013 used a validated instrument (Tinnitus Handicap Questionnaire (THQ)) to measure improvement in tinnitus. In this cross-over study the authors did not report the results of the two phases separately, but reported that $5 \%$ of patients $(5 / 93)$ treated with zinc had improvement in their tinnitus. In the placebo group, $2 \%$ of patients (2/94) had improvement in their tinnitus at four months of follow-up, with no significant difference between the groups (risk ratio (RR) 2.53, $95 \%$ confidence interval $(\mathrm{Cl}) 0.50$ to $12.70, \mathrm{P}=0.26$; very low-quality evidence (Analysis 1.1).

\section{Adverse effects of treatment with oral zinc supplementation}

Coelho 2013 reported that adverse effects were mild and only one participant receiving zinc stopped the trial because of indigestion. One patient in the placebo group dropped out because of constipation and one because of a metallic taste. Arda 2003 reported that two patients had mild gastric symptoms. Paaske 1991 stated that there were no side effects that could be attributed to the intervention.

\section{Secondary outcomes}

\section{Quality of life}

This outcome was not assessed in the included studies.

\section{Change in socioeconomic impact associated with work}

This outcome was not assessed in the included studies.

\section{Change in anxiety and depression disorders}

This outcome was not assessed in the included studies.

\section{Change in psychoacoustic parameters}

This outcome was not assessed in the included studies.

\section{Change in tinnitus loudness}

Arda 2003 reported no significant differences between the zinc and placebo group in the mean tinnitus loudness after eight weeks: 49.9 (21.97) dB and 59.61 (24.96) dB, respectively (mean difference (MD) $-9.71,95 \% \mathrm{Cl}-25.53$ to $6.11, \mathrm{P}=0.23$; very low-quality evidence). Coelho 2013 measured tinnitus loudness on a scale of 0 to 100 after four months and reported no significant difference between the zinc and placebo group: mean tinnitus loudness rating scores 68.1 (18.7) and 67.6 (20.2), respectively (MD $0.50,95 \% \mathrm{Cl}-5.08$ to $6.08, \mathrm{P}$ = 0.86; very low-quality evidence) (Analysis 1.2).

\section{Change in overall severity of tinnitus}

Arda 2003 reported severity of tinnitus using a non-validated scale ( 0 to 7 ) and found no significant difference in subjective tinnitus scores between the zinc and placebo groups at the end of eight weeks of follow-up (MD $-1.41,95 \% \mathrm{Cl}-2.97$ to $0.15, \mathrm{P}=0.08$; very low-quality evidence) (Analysis 1.3). Paaske 1991 also evaluated improvement of tinnitus using a non-validated instrument (a scale of 0 to 10 , where 0 means no tinnitus and 10 severe and unbearable tinnitus). After eight weeks, $8.7 \%(2 / 23)$ of those treated with zinc and $8 \%(2 / 25)$ of those who received placebo had tinnitus improvement, a non-significant difference (RR $1.09,95 \% \mathrm{Cl} 0.17$ to $7.10, P=0.93$; very low-quality evidence) (Analysis 1.4).

\section{Change in thresholds on pure tone audiometry}

This outcome was not assessed in the included studies.

\section{DISCUSSION}

\section{Summary of main results}

See Summary of findings for the main comparison.

Despite the widespread description of zinc as a potential treatment for tinnitus, we identified only three studies involving a total of 209 participants for inclusion in this review. These studies had differences in participant selection, length of follow-up and outcome measurement, precluding a meta-analysis. All studies assessed improvement in tinnitus as a primary outcome, but only one used a validated instrument to measure this outcome (Tinnitus Handicap Questionnaire (THQ)) (Coelho 2013). The authors of this cross-over study did not report the results of the two phases separately and they found no significant difference between the groups at four months of follow-up (very low-quality evidence). A second study reported the severity of tinnitus using a non-validated 0 to 7 scale and found no significant difference in subjective tinnitus scoring between the zinc and placebo groups (very low-quality evidence) (Arda 2003). The third study also evaluated tinnitus improvement using a non-validated 0 to 10 scale and found a nonsignificant difference (very low-quality evidence) (Paaske 1991).

Two studies reported mild adverse effects with zinc supplementation (Arda 2003; Coelho 2013), while Paaske 1991 did not report side effects that could be attributed to the intervention.

Change in tinnitus loudness (one of our secondary outcomes) was measured in different ways in two studies (Arda 2003; Coelho 2013), but there were no significant differences between the zinc and placebo groups. 


\section{Overall completeness and applicability of evidence}

The number of participants included in this review was small and this is a limiting factor in the assessment of the evidence. Since there are different causes of tinnitus and clinical manifestation usually differs between patients, a larger sample size with different subgroups of patients with this symptom is needed. It is also important to distinguish between clinically significant and nonsignificant tinnitus, because many patients have tinnitus that has a non-significant impact in their lives (Davis 2000). Samples also need to be paired according to audiometric parameters, because although the majority of patients with tinnitus have hearing loss, a small subgroup has normal audiometry and this group can have different behaviour regarding tinnitus loudness.

Although there is a high prevalence of tinnitus worldwide, there are relatively few studies on this topic, especially in the area of treatment. In general, these studies look at tinnitus improvement as their primary outcome while secondary outcomes usually include quality of life, change in socioeconomic impact, anxiety and depression disorders and psychoacoustic parameters, while change in thresholds on pure tone audiometry is seldom assessed. This last parameter is important because, contrary to the subjective nature of the other outcomes, it is an objective measure.

This systematic review found no evidence that oral zinc supplementation is effective for the treatment of tinnitus and raised more questions than answers on this issue.

\section{Quality of the evidence}

The included studies had moderate to high risk of bias. None adequately described the randomisation process and only one reported concealed allocation and was double-blind. Another study was unclear about blinding and the third was an open study. The fact that we only identified three studies that tested zinc supplementation for tinnitus raises the possibility of publication bias. The small sample size of the studies increases the risk of uncertainty in the estimates. Therefore, we classified the overall quality of the evidence in this review as very low.

\section{Potential biases in the review process}

We conducted a comprehensive search in a wide range of databases with no language restrictions. To reduce the risk of bias, two independent authors screened the trials identified by the literature search and examined the full text of selected studies for compliance with the eligibility criteria. Both authors assessed the risk of bias of the included studies and extracted data. The authors of this review were not blinded to the authorship and origin of the included studies; this could have introduced bias.

All excluded studies were not randomised controlled trials or did not meet the inclusion criteria. We used all available results in the included studies that were related to our primary and secondary outcomes.
We departed from the protocol by including in the review the results of one of our secondary outcomes (tinnitus severity) measured by non-validated scales.

\section{Agreements and disagreements with other studies or reviews}

We have not identified any other systematic reviews in the literature that have assessed zinc for the treatment of tinnitus. However, there are descriptive studies and experience reports by experts, primarily otolaryngologists, which consider the possible efficacy of this treatment (Person 2004; Shambaugh 1986). Some authors and also websites (as cited by Person 2010) have encouraged the use of zinc to treat tinnitus. Although based on very low-quality evidence, the findings of this review cannot support the conclusions of these authors and websites.

\section{AUTHORS' CONCLUSIONS}

\section{Implications for practice}

Despite the claims of many authors that zinc could be an option for the treatment of tinnitus, there are few studies on this topic. We found no evidence that the use of oral zinc supplementation improves symptoms in adults with tinnitus.

\section{Implications for research}

Researchers should be encouraged to conduct high-quality studies to elucidate any potential role of zinc in the treatment of tinnitus. Future trials should randomise patients with tinnitus to receive zinc supplementation or placebo. Validated tinnitus questionnaires should be used as a measurement tool before, during and after treatment and results should be reported for each subgroup of patients with tinnitus (presence or not of hearing loss; age; occurrence or not of limbic recruitment). Patients treated with zinc should also have an audiological follow-up, because there is some evidence to indicate that pure tone thresholds can be modified during treatment (Shambaugh 1986). Outcomes such as quality of life and socioeconomic impact of the treatment should also be evaluated.

\section{ACKNOWLEDGEMENTS}

The authors would like to thank Alvaro Nagib Atallah for his friendly encouragement in the development and implementation of this study.

We are grateful for the essential assistance of the Brazilian Cochrane Centre in the development of the study protocol and we also thank Cochrane ENT, especially Gemma Sandberg, Samantha Faulkner and Jenny Bellorini, for their valuable contribution to the development of this review.

This project was supported by the National Institute for Health Research, via Cochrane Infrastructure, Cochrane Programme Grant or Cochrane Incentive funding to Cochrane ENT. The views and opinions expressed therein are those of the authors and do not necessarily reflect those of the Systematic Reviews Programme, NIHR, NHS or the Department of Health. 


\section{REFERE N CES}

\section{References to studies included in this review}

Arda 2003 \{published data only\}

Arda HN, Tuncel U, Akdogan O, Ozluoglu LN. The role of zinc in the treatment of tinnitus. Otology \& Neurotology 2003;24(1):86-9.

\section{Coelho 2013 \{published data only\}}

Coelho C. Zinc to treat tinnitus in the elderly: a randomized placebo controlled crossover trial. 6th International TRI Conference on Tinnitus; 2012 June 13-16; Bruges, Belgium. 2012.

* Coelho C, Witt SA, Ji H, Hansen MR, Gantz B, Tyler R. Zinc to treat tinnitus in the elderly: a randomized placebo controlled crossover trial. Otology \& Neurotology 2013;34(6):1146-54.

\section{Paaske 1991 \{published data only\}}

Paaske PB, Pedersen CB, Kjems G, Sam IL. Zinc therapy of tinnitus. A placebo-controlled study. Ugeskrift for Laeger 1990;152:2473-5.

* Paaske PB, Pedersen CB, Kjems G, Sam ILK. Zinc in the management of tinnitus. Placebo-controlled trial. Annals of Otology, Rhinology and Laryngology 1991;100(8):647-9.

\section{References to studies excluded from this review}

\section{Gersdorff 1987 \{published data only\}}

Gersdorff M, Robillard T, Stein F, Declaye X, Vanderbemden S. A clinical correlation between hypozincemia and tinnitus. Archives of Oto-Rhino-Laryngology 1987;244:190-3.

\section{Ochi 1997 \{published data only\}}

Ochi K, Ohashi T, Kinoshita H, Akagi M, Kikuchi H, Mitsui M, et al. The serum zinc level in patients with tinnitus and the effect of zinc treatment. Journal of Otolaryngology of Japan 1997; 100:915-9.

\section{Ochi 2003 \{published data only\}}

Ochi K, Kinoshita H, Kenmochi M, Nishino H, Ohashi T. Zinc deficiency and tinnitus. Auris Nasus Larynx 2003;30:S25-8.

\section{Person 2004 \{published data only\}}

Person OC, Nardi JC, Féres MCLC. The relationship between hypozincemia and tinnitus [A relação entre hipozincemia e zumbido]. Revista Brasileira de Otorrinolaringologia 2004;70:361-7.

\section{Person 2010 \{published data only\}}

Person OC, Nardi JC, Féres MCLC. Zinc supplement modifies auditory brainstem responses in patients with tinnitus. Journal of International Advanced Otology 2010;6:173-82.

\section{Additional references}

\section{Adjamian 2009}

Adjamian P, Sereda M, Hall DA. The mechanisms of tinnitus: perspectives from human functional neuroimaging. Hearing Research 2009;253:15-31.

\section{Andersson 2009}

Andersson G. Tinnitus patients with cognitive problems: causes and possible treatments. Hearing Journal 2009;62:27-8,30.

\section{Biesinger 2011}

Biesinger E, Del Bo L, De Ridder D, Goodey R, Herraiz C, Kleinjung T, et al. Algorithm for the diagnostic \& therapeutic management of tinnitus. http://www.tinnitusresearch.org/en/ documents/downloads/TRI_Tinnitus_Flowchart.pdf (accessed 16 June 2015).

\section{Buss 1998}

Buss E, Hall III JW, Grose JH, Hatch DR. Perceptual consequences of peripheral hearing loss: do edge effects exist for abrupt cochlear lesions? . Hearing Research 1998;125:98-108.

\section{Cima 2012}

Cima RF, Maes IH, Joore MA, Scheyen DJ, El Refaie A, Baguley DM, et al. Specialised treatment based on cognitive behaviour therapy versus usual care for tinnitus: a randomised controlled trial. Lancet 2012;379:1951-9.

\section{Crönlein 2007}

Crönlein T, Langguth B, Geisler P, Hajak G. Tinnitus and insomnia. Progress in Brain Research 2007;166:227-33.

\section{Davis 2000}

Davis A, El Rafaie A. Epidemiology of tinnitus. In: Richard Tyler editor(s). Tinnitus Handbook. San Diego: Singular Publishing Group, 2000.

\section{Deeks 2011}

Deeks JJ, Higgins JPT, Altman DG (editors). Chapter 9: Analysing data and undertaking meta-analysis. In: Higgins JPT, Green $S$ (editors). Cochrane Handbook for Systematic Reviews of Interventions Version 5.1.0 [updated March 2011]. The Cochrane Collaboration, 2011. Available from www.cochranehandbook.org.

\section{Department of Health 2009}

Department of Health. Provision of Services for Adults with Tinnitus. A Good Practice Guide. London: Central Office of Information, 2009.

\section{Dietrich 2001}

Dietrich V, Nieschalk M, Stoll W, Rajan R, Pantev C. Cortical reorganization in patients with high frequency cochlear hearing loss. Hearing Research 2001;158:95-101. 


\section{Dobie 1999}

Dobie RA. A review of randomized clinical trials in tinnitus. Laryngoscope 1999;109:1202-11.

\section{Dong 2010}

Dong S, Rodger J, Mulders WH, Robertson D. Tonotopic changes in GABA receptor expression in guinea pig inferior colliculus after partial unilateral hearing loss. Brain Research 2010;1342:24-32.

\section{Drescher 1992}

Drescher MJ, Drescher DG. Glutamate, of the endogenous primary a-amino acids, is specifically released from hair cells by elevated extracellular potassium. Journal of Neurochemistry 1992;59:93-8.

\section{Eggermont 2004}

Eggermont JJ, Roberts LE. The neuroscience of tinnitus. Trends in Neuroscience 2004;27:676-82.

\section{Eggermont 2010}

Eggermont J, Roberts L, Caspary D, Shore S, Melcher J, Kaltenbach J. Ringing ears: the neuroscience of tinnitus. Journal of Neuroscience 2010;30:14972-9.

\section{El-Shunnar 2011}

El-Shunnar S, Hoare DJ, Smith S, Gander PE, Kang S, Fackrell K, et al. Primary care for tinnitus: practice and opinion among GPs in England. Journal of Evaluation in Clinical Practice 2011;17:684-92.

\section{Elbourne 2002}

Elbourne DR, Altman DG, Higgins JP, Curtin F, Worthington HV, Vail A. Meta-analyses involving cross-over trials: methodological issues. International Journal of Epidemiology 2002;31(1):140-9.

\section{Engineer 2011}

Engineer ND, Riley JR, Seale JD, Vrana WA, Shetake JA, Sudanagunta SP, et al. Reversing pathological neural activity using targeted plasticity. Nature 2011;470:101-4.

\section{Fowler 1944}

Fowler EP. Head noises in normal and disordered ears: significance, measurement, differentiation and treatment. Archives of Otolaryngology 1944;39:490-503.

\section{Frederickson 2000}

Frederickson CJ, Suh SW, Silva D, Thompson RB. Importance of zinc in the central nervous system: the zinc-containing neuron. Journal of Nutrition 2000;130(5 Suppl):14715-835.

\section{Guitton 2003}

Guitton MJ, Caston J, Ruel J, Johnson RM, Pujol R, Puel J-L. Salicylate induces tinnitus through activation of cochlear NMDA receptors. Journal of Neuroscience 2003;23:3944-52.

\section{Hahn 2008}

Hahn A, Radkova R, Achiemere G, Klement V, Alpini D, Strouhal J. Multimodal therapy for chronic tinnitus. International Tinnitus Journal 2008;14:69-71.

\section{Hall 2011}

Hall D, Láinez M, Newman C, Sanchez T, Egler M, Tennigkeit F, et al. Treatment options for subjective tinnitus: self reports from a sample of general practitioners and ENT physicians within Europe and the USA. BMC Health Services Research 2011;11(1):302.

\section{Hallam 1988}

Hallam RS, Jakes SC, Hinchcliffe R. Cognitive variables in tinnitus annoyance. British Journal of Clinical Psychology 1988;27:213-22.

\section{Han 2009}

Han BI, Lee HW, Kim TY, Lim JS, Shin KS. Tinnitus: characteristics, causes, mechanisms, and treatments. Journal of Clinical Neurology 2009;5:11-9.

\section{Handbook 2011}

Higgins JPT, Green S (editors). Cochrane Handbook for Systematic Reviews of Interventions Version 5.1.0 [updated March 2011]. The Cochrane Collaboration, 2011. Available from www.cochrane-handbook.org.

\section{Henry 2004}

Henry JA, Snow JB (editors). Tinnitus: Theory and Management. Ontario: BC Becker Inc, 2004.

\section{Henry 2005}

Henry JA, Dennis KC, Schechter MA. General review of tinnitus: prevalence, mechanisms, effects, and management. Journal of Speech, Language, and Hearing Research 2005;48:1204-35.

\section{Henry 2008}

Henry JA, Zaugg TL, Myers PJ, Schechter MA. The role of audiological evaluation in progressive audiologic tinnitus management. Trends in Amplification 2008;12(3):170-87.

\section{Higgins 2003}

Higgins JPT, Thompson SG, Deeks JJ, Altman DG. Measuring inconsistency in meta-analysis. BMJ 2003;327(7414):555-7.

\section{Hiller 2006}

Hiller W, Goebel G. Factors influencing tinnitus loudness and annoyance. Archives of Otolaryngology -- Head and Neck Surgery 2006;132:1323-30.

\section{Hoare 2011}

Hoare DJ, Hall DA. Clinical guidelines and practice: a commentary on the complexity of tinnitus management. Evaluation and the Health Professions 2011;34(4):413-20.

\section{Hoare 2011a}

Hoare DJ, Kowalkowski V, Kang S, Hall DA. Systematic review and meta-analyses of RCTs examining tinnitus management. Laryngoscope 2011;121:1555-64.

\section{Hoare 2014}

Hoare DJ, Edmondson-Jones M, Sereda M, Akeroyd MA, Hall D. Amplification with hearing aids for patients with tinnitus and co-existing hearing loss. Cochrane Database of Systematic Reviews 2014, Issue 1. [DOI: 10.1002/14651858.CD010151.pub2] 


\section{Hobson 2012}

Hobson J, Chisholm E, El Refaie A. Sound therapy (masking) in the management of tinnitus in adults. Cochrane Database of Systematic Reviews 2012, Issue 11. [DOI: 10.1002/14651858.CD006371.pub3]

\section{Jastreboff 1988}

Jastreboff PJ, Brennan JF, Coleman JK, Sasaki CT. Phantom auditory sensation in rats: an animal model for tinnitus. Behavioral Neuroscience 1988;102:811-22.

\section{Jastreboff 1990}

Jastreboff PJ. Phantom auditory perception (tinnitus): mechanisms of generation and perception. Neuroscience Research 1990;8:221-54.

\section{Jastreboff 2004}

Jastreboff PJ, Hazell JWP. Tinnitus Retraining Therapy. Implementing the Neurophysiological Model. Cambridge: Cambridge University Press, 2004.

\section{Kluk 2006}

Kluk K, Moore BCJ. Dead regions in the cochlea and enhancement of frequency discrimination: effects of audiogram slope, unilateral versus bilateral loss, and hearing-aid use. Hearing Research 2006;221:1-15.

\section{Kuk 1990}

Kuk FK, Tyler RS, Russell D, Jordan H. The psychometric properties of a tinnitus handicap questionnaire. Ear and Hearing 1990;11:434-45.

\section{König 2006}

König O, Schaette R, Kempter R, Gross M. Course of hearing loss and occurrence of tinnitus. Hearing Research 2006;221:59-64.

\section{MacFadden 1999}

MacFadden SL, Ding D, Burkard RF, Jiang H, Reaume AG, Flood DG, et al. $\mathrm{Cu} / \mathrm{Zn}$ SOD deficiency potentiates hearing loss and cochlear pathology in aged 129, CD-1 mice. Journal of Comparative Neurology 1999;413(1):101-12.

\section{Marciano 2003}

Marciano E, Varrabba L, Giannini P, Sementina C, Verde P, Bruno $C$, et al. Psychiatric comorbidity in a population of outpatients affected by tinnitus. International Journal of Audiology 2003;42:4-9.

\section{Martines 2010}

Martines F, Bentivegna D, Di Piazza F, Martines E, Sciacca V, Martinciglio G. Investigation of tinnitus patients in Italy: clinical and audiological characteristics. International Journal of Otolaryngology 2010 Jun 23 [Epub ahead of print].

\section{Martinez-Devesa 2010}

Martinez-Devesa P, Perera R, Theodoulou M, Waddell A. Cognitive behavioural therapy for tinnitus. Cochrane Database of Systematic Reviews 2010, Issue 9. [DOI: 10.1002/14651858.CD005233.pub3]

\section{McDermott 1998}

McDermott HJ, Lech M. Loudness perception and frequency discrimination in subjects with steeply sloping hearing loss: possible correlates of neural plasticity. Journal of the Acoustical Society of America 1998;104:2314-25.

\section{Meikle 2012}

Meikle MB, Henry JA, Griest SE, Stewart BJ, Abrams HB, McArdle R, et al. The Tinnitus Functional Index: development of a new clinical measure for chronic, intrusive tinnitus. Ear and Hearing 2012;33:153-76.

\section{Melcher 2013}

Melcher JR, Knudson IM, Levine RA. Subcallosal brain structure: correlation with hearing threshold at supra-clinical frequencies (>8 kHz), but not with tinnitus. Hearing Research 2013;295:79-86. [DOI: 10.1016/j.heares.2012.03.013]

\section{Middleton 2011}

Middleton JW, Kiritanid T, Pedersen C, Turner JG, Shepherd GMG, Tzounopoulos T. Mice with behavioral evidence of tinnitus exhibit dorsal cochlear nucleus hyperactivity because of decreased GABAergic inhibition. Proceedings of the National Academy of Science 2011;108:7601-6.

\section{Moore 2009}

Moore BCJ, Vinay SN. Enhanced discrimination of lowfrequency sounds for subjects with high-frequency dead regions. Brain 2009;132:524-36.

\section{Mulders 2010}

Mulders WH, Seluakumaran K, Robertson D. Efferent pathways modulate hyperactivity in inferior colliculus. Journal of Neuroscience 2010;30:9578-87.

\section{Møller 2000}

Møller AR. Similarities between severe tinnitus and chronic pain. Journal of the American Academy of Audiology 2000;11:115-24.

\section{Mühlnickel 1998}

Mühlnickel W, Elbert T, Taub E, Flor H . Reorganization of auditory cortex in tinnitus (plasticity magnetic source imaging). Proceedings of the National Academy of Sciences of the United States of America 1998;95:10340-3.

\section{Newman 1996}

Newman CW, Jacobson GP, Spitzer JB. Development of the Tinnitus Handicap Inventory. Archives of Otolaryngology -- Head and Neck Surgery 1996;122:143-8.

\section{Noreña 2005}

Noreña AJ, Eggermont JJ. Enriched acoustic environment after noise trauma reduces hearing loss and prevents cortical map reorganization. Journal of Neuroscience 2005;25:699-705.

\section{Noreña 2011}

Noreña AJ. An integrative model of tinnitus based on a central gain controlling neural sensitivity. Neuroscience and Biobehavioral Reviews 2011;35:1089-109. 


\section{Phillips 2010}

Phillips JS, McFerran D. Tinnitus Retraining Therapy (TRT) for tinnitus. Cochrane Database of Systematic Reviews 2010, Issue 3. [DOI: 10.1002/14651858.CD007330.pub2]

\section{Pilati 2012}

Pilati N, Large C, Forsythe ID, Hamann M. Acoustic overexposure triggers burst firing in dorsal cochlear nucleus fusiform cells. Hearing Research 2012;283:98-106.

\section{Ratnayake 2009}

Ratnayake SA, Jayarajan V, Bartlett J. Could an underlying hearing loss be a significant factor in the handicap caused by tinnitus?. Noise and Health 2009;11:156-60.

\section{Rauschecker 1999}

Rauschecker JP. Auditory cortical plasticity: a comparison with other sensory systems. Trends in Neurosciences 1999;22:74-80.

\section{Rauschecker 2010}

Rauschecker JP, Leaver AM, Mühlau M. Tuning out the noise: limbic-auditory interaction in tinnitus. Neuron 2010;66:819-26.

\section{RevMan 2014 [Computer program]}

The Nordic Cochrane Centre, The Cochrane Collaboration. Review Manager (RevMan). Version 5.3. Copenhagen: The Nordic Cochrane Centre, The Cochrane Collaboration, 2014.

\section{Rief 2005}

Rief W, Weise C, Kley N, Martin A. Psychophysiologic treatment of chronic tinnitus: a randomized clinical trial. Psychosomatic Medicine 2005;67:833-8.

\section{Sahley 2001}

Sahley TL, Nodar RH. A biochemical model of peripheral tinnitus. Hearing Research 2001;152:43-54.

\section{Sanchez 2002}

Sanchez TG, Ferrari GMS. The control of tinnitus through hearing aids: suggestions for optimal use [0 controle do zumbido por meio de prótese auditiva: sugestões para otimização do uso]. Pró-Fono Revista de Atualização Científica 2002;14:111-8.

\section{Schaette 2006}

Schaette R, Kempter R. Development of tinnitus-related neuronal hyperactivity through homeostatic plasticity after hearing loss: a computational model. European Journal of Neuroscience 2006;23:3124-38.

\section{Schaette 2011}

Schaette R, McAlpine D. Tinnitus with a normal audiogram: physiological evidence for hidden hearing loss and computational model. Journal of Neuroscience 2011;31:13452-7.

\section{CHARACTERISTICS OF STUDIES}

Characteristics of included studies [ordered by study ID]

\section{Seki 2003}

Seki S, Eggermont JJ. Changes in spontaneous firing rate and neural synchrony in cat primary auditory cortex after localized tone-induced hearing loss. Hearing Research 2003;180:28-38.

\section{Shambaugh 1985}

Shambaugh Jr GE. Zinc and presbyacusis. American Journal of Otolaryngology 1985;6:116-7.

\section{Shambaugh 1986}

Shambaugh Jr GE. Zinc for tinnitus, imbalance, and hearing loss in the elderly. American Journal of Otology 1986;7(6):476-7.

\section{Tass 2012}

Tass PA, Adamchic I, Freund H-J, von Stackelberg T, Hauptmann C. Counteracting tinnitus by acoustic coordinated reset neuromodulation. Restorative Neurology and Neuroscience 2012;30:137-59.

\section{Thai-Van 2002}

Thai-Van H, Micheyl C, Noreña A, Collet L. Local improvement in auditory frequency discrimination is associated with hearing loss slope in subjects with cochlear damage. Brain 2002;125:524-37.

\section{Thai-Van 2003}

Thai-Van H, Micheyl C, Moore BCJ, Collet L. Enhanced frequency discrimination near the hearing loss cut-off: a consequence of central auditory plasticity induced by cochlear damage?. Brain 2003;126:2235-45.

\section{Vanneste 2012}

Vanneste S, De Ridder D. The auditory and non-auditory brain areas involved in tinnitus. An emergent property of multiple parallel overlapping subnetworks. Frontiers in Systems Neuroscience 2012;6:31.

\section{Weisz 2005}

Weisz N, Moratti S, Meinzer M, Dohrmann K, Elbert T. Tinnitus perception and distress is related to abnormal spontaneous brain activity as measured by magnetoencephalography. PLOS Medicine 2005;2:e153.

\section{Wilson 1991}

Wilson PH, Henry J, Bowen M, Haralambous G. Tinnitus Reaction Questionnaire: psychometric properties of a measure of distress associated with tinnitus. Journal of Speech and Hearing Research 1991;34:197-201.

* Indicates the major publication for the study 
Arda 2003

\begin{tabular}{ll}
\hline Methods & Allocation: randomised, placebo-controlled clinical trial \\
Design: parallel-group & Number: 50 \\
Age: range 21 to 74 years; mean $55 \pm 14.3$ (zinc group) and $51.2 \pm 12.8$ (placebo group) \\
Gender: zinc group included 16 women ( $57.1 \%)$ and 12 men (42.9\%); placebo group included 9 women \\
$(69.2 \%)$ and 4 men ( $30.8 \%)$ \\
Setting: single centre; Ankara, Turkey \\
Eligibility criteria: the inclusion criteria were that patients had no pathologic conditions of the ear, \\
nose and throat that might be responsible for tinnitus \\
Exclusion criteria: not reported \\
Baseline characteristics: there was no significant difference between the treatment category of the \\
tinnitus, or the prevalence of intermittent versus continuous tinnitus, nor were the mean durations of \\
the tinnitus significantly different between groups
\end{tabular}

\begin{tabular}{ll}
\hline Interventions & Intervention group: 50 mg elemental zinc daily for 8 weeks $(n=28)$ \\
Comparator group: placebo $(n=13)$
\end{tabular}

Outcomes

Primary outcome: improvement of tinnitus: a decrease in tinnitus loudness by at least $10 \mathrm{~dB}$ was accepted as clinically favourable progress. A decrease of more than 1 point on a subjective non-validated scale (0 to 7) for tinnitus was accepted as valid

\begin{tabular}{ll}
\hline Funding sources & Not reported \\
\hline Declarations of interest & Not reported \\
\hline
\end{tabular}

Notes

Participants lost to follow-up: $2 / 30(6.7 \%)$ in the zinc group; $7 / 20(35.0 \%)$ in the placebo group

8 weeks follow-up

Trials register: not found

\section{Risk of bias}

\begin{tabular}{lll}
\hline Bias & Authors' judgement & Support for judgement \\
\hline $\begin{array}{l}\text { Random sequence genera- } \\
\text { tion (selection bias) }\end{array}$ & Unclear risk & Randomisation method not reported \\
\hline $\begin{array}{l}\text { Allocation concealment } \\
\text { (selection bias) }\end{array}$ & Unclear risk & Not reported \\
\hline
\end{tabular}

Blinding of participants $\quad$ Unclear risk
and personnel (perfor-
mance bias)
All outcomes

\begin{tabular}{lll}
\hline $\begin{array}{l}\text { Blinding of outcome as- } \\
\text { sessment (detection bias) } \\
\text { All outcomes }\end{array}$ & Unclear risk & The authors did not report the blinding of outcome assessment \\
\hline $\begin{array}{l}\text { Incomplete outcome data } \\
\text { (attrition bias) }\end{array}$ & High risk & $\begin{array}{l}\text { Losses } 2 / 30(6.7 \%) \text { and } 7 / 20(33.8 \%) \text { in the zinc group. ITT analysis not per- } \\
\text { formed. }\end{array}$
\end{tabular}


Arda 2003 (Continued)

All outcomes

\begin{tabular}{|c|c|c|}
\hline $\begin{array}{l}\text { Selective reporting (re- } \\
\text { porting bias) }\end{array}$ & Low risk & $\begin{array}{l}\text { There was no evidence of selective reporting based on comparison of the } \\
\text { methods and results sections }\end{array}$ \\
\hline
\end{tabular}

Other bias Low risk There was no evidence of other bias

Coelho 2013

\begin{tabular}{|c|c|}
\hline Methods & $\begin{array}{l}\text { Allocation: randomised, placebo-controlled, double-blind clinical trial } \\
\text { Design: cross-over }\end{array}$ \\
\hline Participants & $\begin{array}{l}\text { Number: } 109 \\
\text { Age: mean age } 67.5 \text { (5.4) (zinc group) and } 67.7 \text { (5.8) (placebo group) } \\
\text { Gender: } 66 \% \text { male } \\
\text { Setting: single centre, patients attending the tinnitus clinic at the Otolaryngology and Head and Neck } \\
\text { Department at the University of lowa } \\
\text { Eligibility criteria: } 60 \text { years or older, tinnitus duration for } 6 \text { months or more, normal copper levels, } \\
\text { generally good health } \\
\text { Exclusion criteria: had a treatable otologic disorder, involved in litigation, presenting or suspected of } \\
\text { having a serious psychiatric problem, involved in other treatments for tinnitus, taking drugs that might } \\
\text { interact with zinc and result in tinnitus, copper deficiency, zinc levels above normal and cognitive im- } \\
\text { pairment } \\
\text { Baseline characteristics: treatment groups were compared at screening for age, sex, tinnitus loca- } \\
\text { tion, duration and quality, mean hearing levels, tinnitus loudness and annoyance and THQ scores, zinc } \\
\text { and copper serum levels, and trial dropouts for potential influences on treatment outcome. No differ- } \\
\text { ences across groups were observed. }\end{array}$ \\
\hline
\end{tabular}

Cross-over study
Phase I
Interventions
Comparator group: placebo for 16 weeks $(n=55)$
Washout: 4 weeks
Phase II
Intervention group: 50 mg elemental zinc for 16 weeks $(n=45)$
Comparator group: placebo for 16 weeks $(n=46)$

Outcomes

Primary outcome: improvement of tinnitus measured by changes of 20 points or greater on the Tinnitus Handicap Questionnaire (THQ)

Secondary outcome: change in tinnitus loudness (0 to 100 scale)

\begin{tabular}{ll}
\hline Funding sources & The study was funded by the Tinnitus Research Initiative (TRI Grant RT 06 10) \\
\hline Declarations of interest & The authors declared that they have no conflicts of interest in the research \\
\hline Notes & Participants lost to follow-up: 20/106 (18.9\%) proportionally distributed between the groups
\end{tabular}


Coelho 2013 (Continued)

Trials register: NCT00683644

\section{Risk of bias}

\begin{tabular}{|c|c|c|}
\hline Bias & Authors' judgement & Support for judgement \\
\hline $\begin{array}{l}\text { Random sequence genera- } \\
\text { tion (selection bias) }\end{array}$ & Unclear risk & Random sequence generation not described \\
\hline $\begin{array}{l}\text { Allocation concealment } \\
\text { (selection bias) }\end{array}$ & Low risk & External allocation (pharmacy department) \\
\hline $\begin{array}{l}\text { Blinding of participants } \\
\text { and personnel (perfor- } \\
\text { mance bias) } \\
\text { All outcomes }\end{array}$ & Low risk & The blinding of participants and personnel was described \\
\hline $\begin{array}{l}\text { Blinding of outcome as- } \\
\text { sessment (detection bias) } \\
\text { All outcomes }\end{array}$ & Low risk & The blinding of outcome assessment was described \\
\hline $\begin{array}{l}\text { Incomplete outcome data } \\
\text { (attrition bias) } \\
\text { All outcomes }\end{array}$ & Unclear risk & Losses 20/106 (18.9\%); ITT analysis \\
\hline $\begin{array}{l}\text { Selective reporting (re- } \\
\text { porting bias) }\end{array}$ & Low risk & $\begin{array}{l}\text { There was no evidence of selective reporting based on comparison of the } \\
\text { methods and results sections }\end{array}$ \\
\hline Other bias & Low risk & There was no evidence of other bias \\
\hline
\end{tabular}

Paaske 1991

Methods Allocation: randomised, placebo-controlled, double-blind clinical trial

Design: parallel-group

Participants

Number: 50

Age: median 57 years, range 29 to 77

Gender: $65 \%$ men

Setting: single centre, audiological clinic

Eligibility criteria: patients with tinnitus to such a degree that they wanted some form of treatment

Exclusion criteria: not described

Baseline characteristics: the duration of tinnitus varied from 3 months to 34 years (median 5 years). 3

of the patients had suffered from tinnitus for less than 6 months. $42(88 \%)$ suffered from constant and 6

$(12 \%)$ from intermittent tinnitus. No significant difference in age between the 2 groups was found.

Interventions

Intervention group: 66 mg elemental zinc daily for 8 weeks $(n=25)$

Comparator group: placebo for 16 weeks $(n=25)$ 
Paaske 1991 (Continued)

Funding sources Not reported

Declarations of interest Not reported

Notes

Participants lost to follow-up: $2 / 50$ (4\%)

Trials register: not found

\begin{tabular}{|c|c|c|}
\hline \multicolumn{3}{|l|}{ Risk of bias } \\
\hline Bias & Authors' judgement & Support for judgement \\
\hline $\begin{array}{l}\text { Random sequence genera- } \\
\text { tion (selection bias) }\end{array}$ & Unclear risk & Random sequence generation not described \\
\hline $\begin{array}{l}\text { Allocation concealment } \\
\text { (selection bias) }\end{array}$ & Unclear risk & Not described \\
\hline $\begin{array}{l}\text { Blinding of participants } \\
\text { and personnel (perfor- } \\
\text { mance bias) } \\
\text { All outcomes }\end{array}$ & Unclear risk & Blinding methods not described \\
\hline $\begin{array}{l}\text { Blinding of outcome as- } \\
\text { sessment (detection bias) } \\
\text { All outcomes }\end{array}$ & Unclear risk & Blinding methods not described \\
\hline $\begin{array}{l}\text { Incomplete outcome data } \\
\text { (attrition bias) } \\
\text { All outcomes }\end{array}$ & Low risk & Losses $2 / 50(4 \%)$ \\
\hline $\begin{array}{l}\text { Selective reporting (re- } \\
\text { porting bias) }\end{array}$ & Low risk & $\begin{array}{l}\text { There was no evidence of selective reporting based on comparison of the } \\
\text { methods and results sections }\end{array}$ \\
\hline Other bias & Low risk & There was no evidence of other bias \\
\hline
\end{tabular}

ITT: intention-to-treat

THQ: Tinnitus Handicap Questionnaire

Characteristics of excluded studies [ordered by study ID]

\begin{tabular}{ll}
\hline Study & Reason for exclusion \\
\hline Gersdorff 1987 & ALLOCATION \\
& Not randomised \\
\hline Ochi 1997 & $\begin{array}{l}\text { ALLCATION } \\
\text { Not randomised }\end{array}$ \\
\hline Ochi 2003 & ALLOCATION \\
\hline Person 2004 & Not randomised \\
\hline
\end{tabular}




\begin{tabular}{ll}
\hline Study & Reason for exclusion \\
\hline Person 2010 & Not randomised \\
& ALLOCATION \\
Not randomised \\
\hline
\end{tabular}

\section{DATA AND ANALYSES}

\section{Comparison 1. Zinc versus placebo}

\begin{tabular}{|c|c|c|c|c|}
\hline Outcome or subgroup title & No. of studies & $\begin{array}{l}\text { No. of partici- } \\
\text { pants }\end{array}$ & Statistical method & Effect size \\
\hline $\begin{array}{l}1 \text { Improvement in tinnitus severity } \\
\text { and disability, measured by a val- } \\
\text { idated tinnitus-specific question- } \\
\text { naire }\end{array}$ & 1 & 187 & Risk Ratio (M-H, Fixed, 95\% Cl) & $2.53[0.50,12.70]$ \\
\hline 2 Tinnitus loudness & 2 & & $\begin{array}{l}\text { Mean Difference (IV, Fixed, 95\% } \\
\mathrm{Cl} \text { ) }\end{array}$ & Subtotals only \\
\hline 2.1 Mean dB & 1 & 41 & $\begin{array}{l}\text { Mean Difference (IV, Fixed, 95\% } \\
\mathrm{CI} \text { ) }\end{array}$ & $-9.71[-25.53,6.11]$ \\
\hline 2.2 Scale 0 to 100 & 1 & 187 & $\begin{array}{l}\text { Mean Difference (IV, Fixed, 95\% } \\
\mathrm{CI} \text { ) }\end{array}$ & $0.5[-5.08,6.08]$ \\
\hline $\begin{array}{l}3 \text { Mean overall severity of tinnitus: } \\
\text { scale } 0 \text { to } 7\end{array}$ & 1 & 41 & $\begin{array}{l}\text { Mean Difference (IV, Fixed, 95\% } \\
\mathrm{CI} \text { ) }\end{array}$ & $-1.41[-2.97,0.15]$ \\
\hline 4 Improvement tinnitus severity & 1 & 48 & Risk Ratio (M-H, Fixed, 95\% Cl) & $1.09[0.17,7.10]$ \\
\hline
\end{tabular}

Analysis 1.1. Comparison 1 Zinc versus placebo, Outcome 1 Improvement in tinnitus severity and disability, measured by a validated tinnitus-specific questionnaire.

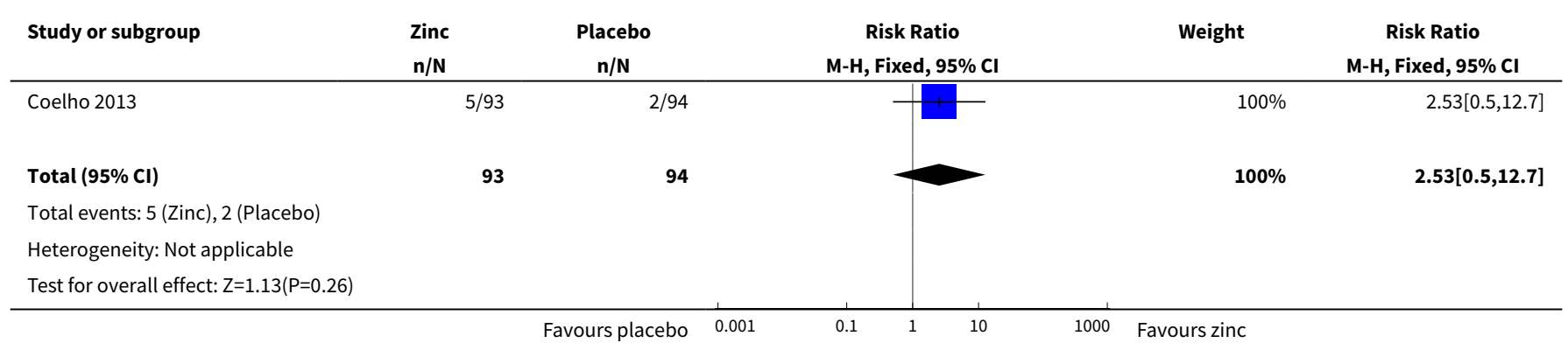


Analysis 1.2. Comparison 1 Zinc versus placebo, Outcome 2 Tinnitus loudness.

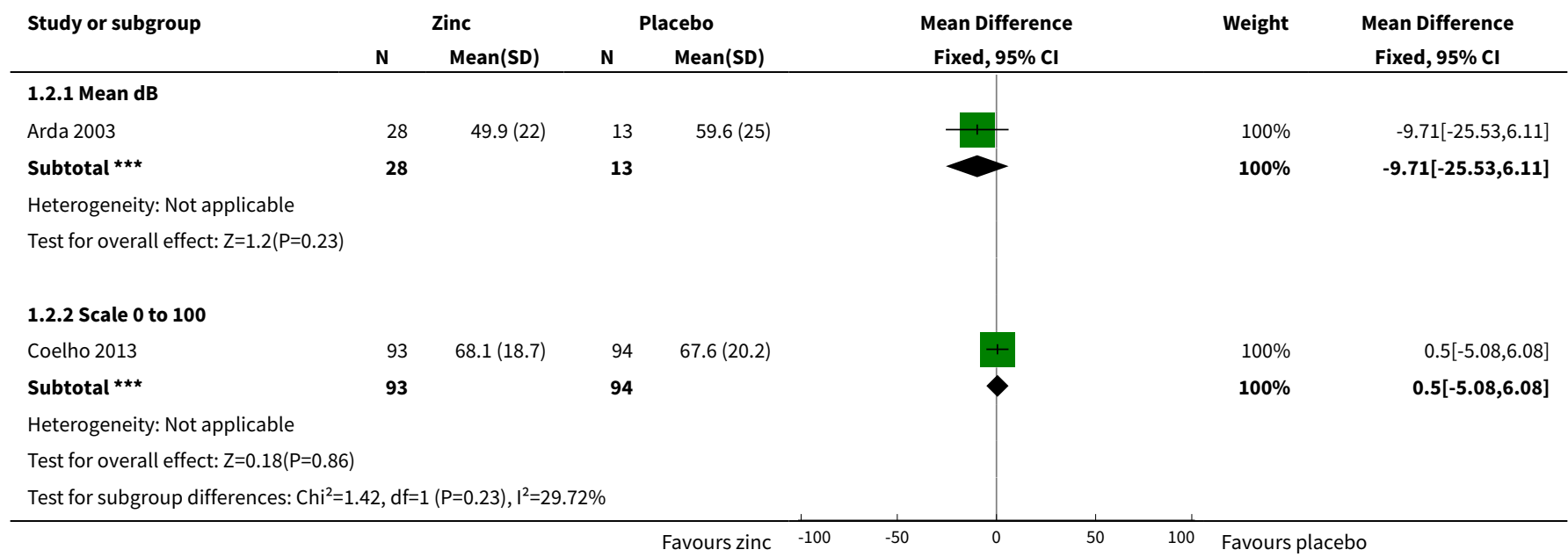

Analysis 1.3. Comparison 1 Zinc versus placebo, Outcome 3 Mean overall severity of tinnitus: scale 0 to 7.

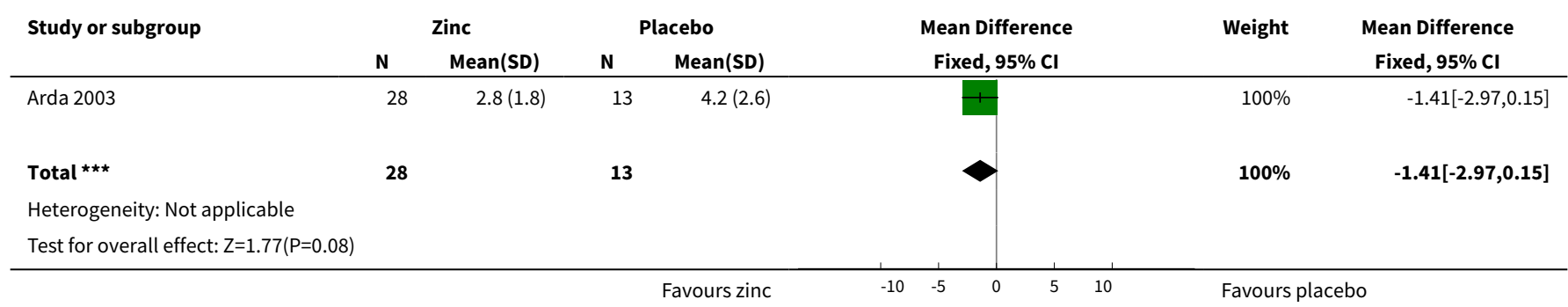

Analysis 1.4. Comparison 1 Zinc versus placebo, Outcome 4 Improvement tinnitus severity.

\begin{tabular}{|c|c|c|c|c|c|}
\hline Study or subgroup & $\begin{array}{l}\text { Zinc } \\
\mathrm{n} / \mathrm{N}\end{array}$ & $\begin{array}{c}\text { Placebo } \\
\mathbf{n} / \mathbf{N}\end{array}$ & $\begin{array}{c}\text { Risk Ratio } \\
\text { M-H, Fixed, 95\% CI }\end{array}$ & Weight & $\begin{array}{c}\text { Risk Ratio } \\
\text { M-H, Fixed, } 95 \% \mathrm{Cl} \\
\end{array}$ \\
\hline Paaske 1991 & $2 / 23$ & $2 / 25$ & - & $100 \%$ & $1.09[0.17,7.1]$ \\
\hline Total $(95 \% \mathrm{Cl})$ & 23 & 25 & & $100 \%$ & $1.09[0.17,7.1]$ \\
\hline \multicolumn{6}{|c|}{ Total events: 2 (Zinc), 2 (Placebo) } \\
\hline \multicolumn{6}{|c|}{ Heterogeneity: Not applicable } \\
\hline
\end{tabular}

\section{AP PE N DICES}

\section{Appendix 1. Tinnitus measurement tools}

TheTinnitus Handicap Inventory (THI) is a self-administered tool to measure the impact of the tinnitus in daily life (Newman 1996). It consists of 25 items that may be answered yes (four points), sometimes (two points) or no (zero points), summing up a total of 100 points, with higher scores corresponding to a higher handicap. The items are divided into three subscales: 
- The functional subscale (F) (11 items) encompasses role limitations in the areas of mental functioning, social/occupational functioning and physical functioning.

- The emotional subscale (E) (nine items) includes items addressing affective responses to tinnitus (anger, frustration, irritability, depression).

- The catastrophic subscale (C) (five items) reflects patients' desperation, inability to escape from tinnitus, perception of having a terrible disease, lack of control and inability to cope.

1. Because of your tinnitus is it difficult for you to concentrate? (F)

2. Does the loudness of your tinnitus make it difficult for you to hear people? (F)

3. Does your tinnitus make you angry? (E)

4. Does your tinnitus make you confused? (F)

5. Because of your tinnitus are you desperate? (C)

6. Do you complain a great deal about your tinnitus? (E)

7. Because of your tinnitus do you have trouble falling asleep at night? (F)

8. Do you feel as though you cannot escape from your tinnitus? (C)

9. Does your tinnitus interfere with your ability to enjoy social activities (such as going out to dinner, to the cinema)? (F)

10.Because of your tinnitus do you feel frustrated? (E)

11.Because of your tinnitus do you feel that you have a terrible disease? (C)

12.Does your tinnitus make it difficult to enjoy life? (F)

13.Does your tinnitus interfere with your job or household responsibilities? (F)

14. Because of your tinnitus do you find that you are often irritable? (F)

15. Because of your tinnitus is it difficult for you to read? (F)

16. Does your tinnitus make you upset? (E)

17. Do you feel that your tinnitus has placed stress on your relationships with members of your family and friends? (E)

18. Do you find it difficult to focus your attention away from your tinnitus and on to other things? (F)

19.Do you feel that you have no control over your tinnitus? (C)

20.Because of your tinnitus do you often feel tired? (F)

21.Because of your tinnitus do you feel depressed? (E)

22.Does your tinnitus make you feel anxious? (E)

23. Do you feel you can no longer cope with your tinnitus? (C)

24.Does your tinnitus get worse when you are under stress? (F)

25.Does your tinnitus make you feel insecure? (E)

According to the score, tinnitus can be classified into five categories:

Category 1: 0 to 16 . Slight (only heard in quiet environments).

Category 2: 18 to 36 . Mild (easily masked by environmental sounds and easily forgotten with activities).

Category 3: 38 to 56. Moderate (noticed in the presence of background noise, though daily activities can still be performed).

Category 4: 58 to 76. Severe (almost always heard, leads to disturbed sleep patterns and can interfere with daily activities).

Category 5: 78 to 100. Catastrophic (always heard, disturbed sleep patterns, difficulty with any activities).

\section{Tinnitus Handicap Questionnaire}

The Tinnitus Handicap Questionnaire is a 27-item tool that measures tinnitus-related handicap (Kuk 1990). The major weakness of this scale is that it focuses solely on the psychological aspect of distress (Newman 1996).

Other tools used for tinnitus evaluation are the Tinnitus Questionnaire (TQ) (Hallam 1988), the Tinnitus Reaction Questionnaire (TRQ) (Wilson 1991) and the Tinnitus Functional Index (TFI) (Meikle 2012).

\section{Appendix 2. Search strategies}

\begin{tabular}{|c|c|c|c|}
\hline CENTRAL & PubMed & EMBASE (Ovid) & $\begin{array}{l}\text { Web of Science (Web of } \\
\text { Knowledge) }\end{array}$ \\
\hline \#1 MeSH descriptor Tinnitus explode all tress & \#1 "Tinnitus" [MeSH] & 1 tinnitus/ & \#3 \#1 AND \#2 \\
\hline \#2 tinnit* & & 2 tinnit* & \#2 TS=(zinc OR hypoz- \\
\hline \#3 \#1 OR \#2 & \#2 tinnit $^{\star}$ & & inc $\left.^{\star}\right)$ \\
\hline
\end{tabular}

Zinc supplementation for tinnitus (Review) 
(Continued)

\#4 MeSH descriptor Zinc explode all trees

\#5 zinc OR hypozinc*

\#6 \#4 OR \#5

\#7 \#3 AND \#6
\#3 (\#1 OR \#2)
31 or 2
\#1 TS=tinnit*
\#4 "Zinc" [MeSH]
4 zinc/
\#5 (zinc* OR hypozinc*)
5 zinc OR hypozinc
\#6 (\#4 OR \#5)
64 or 5
\#7 (\#3 AND \#6)
73 and 6

\begin{tabular}{lll}
\hline CINAHL (EBSCO) & ICTRP & $\begin{array}{c}\text { ClinicalTrials.gov (via } \\
\text { the CRS) }\end{array}$ \\
\hline S7 S3 AND S6 & tinnit* AND zinc OR tinnit* $^{*}$ tinnitus AND (zinc OR $\quad$ (TW:tinnit\$ or & hypozinc) \\
S6 S4 OR S5 & AND hypozinc*Aúfeno OR & TW:Zumbido) AND (TW:Z- \\
S5 TX zinc OR hypozinc* or TW:hypozinc\$) & \\
S4 (MH "Zinc") & & \\
S3 S1 OR S2 & & \\
S2 TX tinnit* & & \\
S1 (MH "Tinnitus") & & \\
\hline
\end{tabular}

\section{CONTRIBUTIONS OF AUTHORS}

Osmar Clayton Person: created the idea; drafted the protocol; screened references; selected studies, extracted data; entered data into RevMan; organised and analysed data; and drafted the review manuscript.

Maria Eduarda dos Santos Puga: participated in drafting the protocol and drafted the review manuscript.

Edina Mariko Koga da Silva: participated in drafting the protocol, organised and analysed data/statistics, and drafted the review manuscript.

Maria Regina Torloni: drafted the protocol; selected studies; extracted data and drafted the review manuscript.

\section{DECLARATIONS OF INTEREST}

Osmar Clayton Person declares no conflicts of interest.

Maria Eduarda dos Santos Puga declares no conflicts of interest.

Edina Mariko Koga da Silva declares no conflicts of interest.

Maria Regina Torloni declares no conflicts of interest.

\section{SOURCES OF SUPPORT}

\section{Internal sources}

- No sources of support supplied

\section{External sources}

- National Institute for Health Research, UK.

Infrastructure funding for Cochrane ENT 


\section{DIFFERENCES BETWEEN PROTOCOL AND REVIEW}

We have specified that we considered cross-over studies for inclusion in Types of studies.

We included in the Unit of analysis issues section: "For trials with a cross-over design, the data would have been included using the results of paired analyses (Elbourne 2002)".

We included the result of two studies that used a non-validated scale to measure the secondary outcome, change in overall severity of tinnitus.

We have moved 'adverse effects' from a secondary to a primary outcome measure.

\section{INDEX TERMS}

\section{Medical Subject Headings (MeSH)}

Administration, Oral; Randomized Controlled Trials as Topic; Surveys and Questionnaires; Tinnitus [*therapy]; Treatment Outcome; Zinc [administration \& dosage] [ ${ }^{\star}$ therapeutic use]

\section{MeSH check words}

Adult; Aged; Humans; Middle Aged 